\title{
Mossy Fiber Growth and Synaptogenesis in Rat Hippocampal Slices in vitro
}

\author{
Michael E. Dailey, JoAnn Buchanan, Dwight E. Bergles, and Stephen J Smith \\ Department of Molecular and Cellular Physiology, Stanford University School of Medicine, Stanford, California 94305-5426
}

Hippocampal slices from early postnatal rat were used to study mossy fiber (MF) growth and synaptogenesis. The ability of MFs to form new giant synapses within isolated tissue slices was established by a series of experiments involving synapsin I immunohistochemistry, electron microscopy, and whole-cell recordings. When hippocampal slices from immature rats were cultured for up to 2 weeks, the distribution of giant MF terminals was similar to that found in vivo. Using a lesioning procedure, we determined that MFs in slices extend and form appropriate synaptic connections with normal target CA3 pyramidal cells. MF terminals were dispersed more widely than normal within the CA3 pyramidal layer after a lesion, but electron microscopy indicated that synaptic junctions were still primarily associated with pyramidal cell dendrites and not the somata. Establishment of functional synaptic input in vitro was confirmed by wholecell recordings of MF-driven excitatory postsynaptic currents ( $50 \mathrm{pA}$ to $1 \mathrm{nA}$ ) in pyramidal cells. The results establish for the first time that an MF projection with appropriate and functional synaptic connections can be formed de novo and not just maintained in excised hippocampal slices.

The cellular dynamics underlying MF growth and synaptogenesis were examined directly by time-lapse confocal imaging of fibers selectively stained with a fluorescent membrane dye (Dil or DiO). MFs growing deep within isolated tissue slices were tipped by small $(5-10 \mu \mathrm{m})$, active growth cones that advanced at variable rates $(5-25 \mu \mathrm{m} / \mathrm{hr})$. Furthermore, dynamic filopodial structures were seen at small varicosities along the length of developing MFs, which may identify nascent en passant synaptic contacts.

The hippocampal slice preparations are shown to support normal development of MF connections and allow for direct visualization of the cellular dynamics of synapse formation in a mammalian CNS tissue environment.

IKey words: synaptogenesis, hippocampus, brain slice, synapsin I, Dil, confocal microscopy, electron microscopy, whole-cell recording, time-lapse imaging]

Received Apr. 22, 1993; revised July 21, 1993; accepted July 29, 1993

This work was supported by NIH Grants NS09027 (M.E.D.) and NS28587 (S.JS.), NIMH Grant MH48108 (Silvio Conte Center for Neuroscience Research), and an NSF Predoctoral Fellowship (D.E.B.). We thank Dr. Pietro DeCamilli (Yale) for generous gifts of synapsin I antiserum and helpful advice on the staining procedure, Dr. Julie Kauer (Duke) for teaching us the organotypic culture technique, Dr. Daniel Madison (Stanford) for the data acquisition program, and Rachana Tiagi for help with the immunohistochemistry. We also thank Drs. Sue Pike and Nancy O'Rourke for critical reading of the manuscript.

Correspondence should be addressed to Dr. Michael E. Dailey, Department of Molecular and Cellular Physiology, Beckman Center, Stanford University School of Medicine, Stanford, CA 94305-5426.

Copyright $(\mathcal{1} 1994$ Society for Neuroscience $0270-6474 / 94 / 141050-19 \$ 05.00 / 0$
Formation of precise synaptic connections during development is critical to the normal functioning of the mammalian CNS, but little is known about the cellular interactions that underlie target neuron selection and synapse formation. Our current understanding of axon-target cell interactions and synaptogenesis has been primarily guided by analysis of static images of fixed tissue (for review, see Vaughn, 1989) and observations of cell dynamics in dissociated cell culture (e.g., Cooper and Smith, 1992). It is now proving feasible to investigate such developmental events in living tissue slices, which combine the accessibility of the in vitro conditions with tissuc complexity that approximates the in situ environment. While in vitro tissue slices hold great promise for studies of neural development, it is necessary to assess the extent to which development proceeds normally in tissue isolated from the brain.

We wanted to determine if neurons in excised slices of developing rat hippocampus extend axons and form appropriate synaptic connections in vitro. The mussy fiber (MF) connection between granule cells of the dentate gyrus (DG) and pyramidal cells of the hippocampal area CA3 is an attractive system for study because (1) the MFs course in a highly lamellar projection (Amaral and Witter, 1989) such that brain slice preparations preserve the normal anatomic pathways and cellular relationships to a great extent, and (2) the synaptic specializations (i.e., giant presynaptic terminals and complex postsynaptic spines) formed between these cell types are large and highly distinctive, making them readily identifiable in both the light and electron microscope (Blackstad and Kjaerheim, 1961; Hamlyn, 1962). Furthermore, hippocampal slices from developing rat brain can be cultured for several days to weeks, and such "organotypic" cultures maintain a high degree of tissue organization (Gähwiler, 1981, 1984a,b). For example, the distribution of Timm-stained MFs (Gähwiler, 1984b), the ultrastructure of MF terminals and corresponding postsynaptic specializations (Zimmer and Gähwiler, 1984; Frotscher and Gähwiler, 1988), and the basic electrophysiological properties of the MF-pyramidal cell connection (Gähwiler, 1984a, 1988) have been examined in cultured slices and have been found thus far to be generally comparable to the in vivo situation.

While the anatomical and physiological properties of the MF system have been well characterized in organotypically cultured slices, the extent to which MFs continue on a normal developmental course in vitro is not known. Since hippocampal tissue for slice cultures is typically obtained at an age when MF growth and synaptogenesis have already commenced (Gähwiler, 1988), it has been difficult to determine conclusively if MF development actually proceeds (or if only the existing MF connections are maintained) after the slices are prepared. Indeed, whether MFs are capable of recognizing and forming new functional 
synaptic contacts with normal target cells in tissue slices is uncertain. Previous work (Zimmer and Gähwiler, 1987) has suggested that, after a lesion, MFs in slice cultures are able to regrow into the appropriate target region (CA3) and elaborate giant synaptic terminals, but an abnormal distribution of MF terminals was observed. Moreover, it has not been determined whether new synaptic contacts are made with the normal cellular domains (apical dendrites) of target pyramidal cells, whether normal synaptic specializations are formed, or whether functional connections are established with pyramidal cells in vitro.

We have therefore attempted to ascertain whether MFs continue to grow and form synaptic connections normally in excised hippocampal slices. Specifically, we wanted to (1) evaluate more thoroughly MF growth and synaptogenesis after a lesion in cultured slices to determine if MFs in vitro make appropriate synaptic contacts with pyramidal cells de novo, and (2) determine if MFs grow along their normal pathway in minimally disturbed slices in vitro. We found that whole-mount fluorescence immunohistochemistry (IHC) using anti-synapsin I (Syn-I) antiserum (DeCamilli et al., 1983a,b) was a useful method of lightlevel visualization of giant MF terminals in tissue slices. Using Syn-I IHC, we observed that the organization of MF giant boutons in slice cultures mirrored the in vivo distribution. Syn-I IHC also showed that after lesioning, MFs in cultured slices grow and form new giant synaptic boutons. Ultrastructural observations indicated that the new giant synaptic terminals were formed in relation to appropriate postsynaptic elements, and electrophysiological methods confirmed that functional synaptic connections were reestablished. The results provide the first direct demonstration that MFs form synaptic contacts de novo with pyramidal neurons in tissue slices. Furthermore, we show directly, by vital fluorescence staining and time-lapse confocal imaging, that MFs in cxcised hippocampal slices continuc to grow along their normal suprapyramidal pathway in vitro. The hippocampal slice preparation is shown to be highly amenable for direct study of axon growth and synaptogenesis in live mammalian CNS tissue.

A preliminary account of a portion of this work has appeared previously (Dailey and Smith, 1991).

\section{Materials and Methods}

Organotypic (roller tube) slice culture. Organotypic slice cultures were prepared following the methods of Gähwiler (1981, 1984a,b). Postnatal day 7 (P7) Sprague-Dawley rats (Bantin \& Kingman; Harlan) were decapitated according to institutional guidelines, and hippocampi were removed and placed in cold saline. A McIllwain tissue chopper (Stoelting) was used to cut $400-\mu \mathrm{m}$-thick slices transverse to the long axis of the hippocampus. Due to the septotemporal developmental gradient (see Cowan et al., 1981), slices were taken from only the middle third of the hippocampus. Individual slices were placed on alcohol-cleaned and sterilized glass coverslips $(11 \times 22 \mathrm{~mm}$, thickness 1$)$ and secured in place with a plasma clot. The clot was made by adding $10 \mu \mathrm{l}$ of heparinized chicken plasma (1 mg/ml; Sigma or Cocalico) and $10 \mu \mathrm{l}$ of thrombin (100 U/ml; Sigma) in Hanks' balanced salt solution (HBSS). The clot served to secure the slice to the coverglass during the culture period, which involved constant gentle rolling to aerate the tissue (Gähwiler, 1981).

Slices were cultured for up to 2 weeks by the roller tube method (Gähwiler, 1981, 1984a,b). Coverslips with slices were placed in culture tubes and rotated at approximately 12 revolutions per hour in a roller drum tilted about $5^{\circ}$ with respect to the horizontal axis. The roller tube contained $1 \mathrm{ml}$ of culture media consisting of $50 \%$ minimum essential medium (MEM) without phenol red, 25\% horse serum, and 25\% HBSS (all from GIBCO), supplemented with dextrose $(6 \mathrm{mg} / \mathrm{ml}$; Sigma). The cultures were maintained at $37^{\circ} \mathrm{C}$, and the media were changed every 4-6 d.
Lesioning of mossy fiber tract. In some slices, the MF tract was transected before the slices were clotted onto the coverglass, following the general procedure of Zimmer and Gähwiler (1987). Lesioning was performed under a dissecting microscope at $10 \times$ magnification with transillumination, which permitted easy visualization of the granule and pyramidal cell layers. $\Lambda$ small, curved scalpel was used to make a lesion through the entire thickness of the slice. The lesion was made perpendicular to the pyramidal cell layer in area CA3 starting just beyond the tip of the lateral (suprapyramidal) blade of the granule cell layer and progressing through the $\mathrm{CA} 3$ pyramidal cell layer to the edge of the slice (see Fig. 6). The location and extent of the lesion were determined by visual inspection of both surfaces of the slice. Complete transection was verified by gently separating the cut ends. Furthermore, injection of DiI into the dentate gyrus (see below) was used to confirm that this procedure produces complete transection of the MF tract at the lesion site (see Fig. 6).

As noted by Zimmer and Gähwiler (1987), the lesioning protocol produced two sets of cultures. In some cultures, the proximal and distal stumps were displaced and consequently a gap formed. In many cultures, however, the stumps became reopposed with no intervening gap. Growth of fibers into CA3 was much more robust in the latter group, and the results presented here were derived from such cultures.

Synapsin I immunohistochemistry. Acute hippocampal slices for immunohistochemistry were derived from Pl-P13 rats. Brains were rapidly removed after decapitation and placed in ice-cold saline. Hippocampi were dissected out and sliced (400- $\mu \mathrm{m}$-thick sections) using a McIllwain tissue chopper, and slices were immediately fixed in $4 \%$ formaldehyde in phosphate-buffered saline (PBS). Free-floating slices were placed in multiwell plates for subsequent rinsing, blocking, and labeling steps (see below). For all steps in the Syn-I immunostaining procedure, the PBS contained $0.45 \mathrm{M} \mathrm{NaCl}$.

To immunostain organotypic cultures, they were briefly washed in PBS and then fixed in 4\% formaldehyde in PBS for $10 \mathrm{~min}$. Cultures were rinsed in PBS and then extracted overnight ( $1-4 \mathrm{~d}$ for acute slices) in $1 \%$ Triton X-100 (Polysciences) with agitation. Blocking was done with $50 \mathrm{~mm} \mathrm{NH}_{4} \mathrm{Cl}$ in PBS (30 min) and then $20 \%$ normal goat serum (NGS) in PBS (30 min). Following a brief rinse in $1 \%$ NGS, cultures were incubated overnight $\left(4^{\circ} \mathrm{C}\right)$ in primary antiserum diluted $(1: 100)$ in PBS containing 1\% NGS. Primary antiserum generated in rabbit against synapsin I was a kind gift of Dr. P. DeCamilli (Yale University). The polyclonal antiserum is known to recognize the synapsin Ia and Ib isoforms (DeCamilli et al., 1983a). After a brief wash, rhodamine-conjugated goat anti-rabbit IgG secondary (1:25; Cappel) was applied for $4 \mathrm{hr}$ (room temperature). The extraction, blocking, and rinsing steps were performed on a rotating stage to provide constant agitation. Coverslips with cultures were rinsed in PBS and mounted for observation in Aqua-Poly/Mount (Polysciences). Free-floating acute slices were secured to a coverslip with a plasma clot before viewing.

DiI labeling and photoconversion. To label MFs in both living and fixed slices, a solution of $0.5 \% \mathrm{DiIC}_{18}(3)(\mathrm{DiI})$ or $\mathrm{DiOC}_{18}$ (3) (DiO; Molecular Probes, catalog \#D-282 and \#D-275, respectively) in dimethylformamide was pressure injected into the hilar region of the dentate gyrus, where MFs converge before entering area CA3. Brief pressure pulses ( $1 \mathrm{msec}, 80 \mathrm{psi}$ ) were delivered to the back of dye-filled glass pipettes (2-5 $\mu \mathrm{m}$ tip diameter) using a Picrospritzer (General Valve).

DiI in some brain slices was photoconverted to a stable electrondense reaction product using established procedures (Sandell and Masland, 1988; McConnell et al., 1989). Briefly, the DiI-labeled slices were fixed in 4\% paraformaldehyde, rinsed in PBS, and subjected to continuous intense illumination with a mercury arc lamp in the presence of

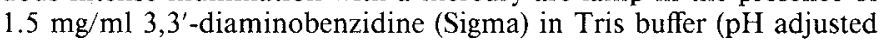
to $\approx 7.4$ with potassium cyanidc). The illumination was continucd until the fluorescence was bleached and dark reaction product was evident as visualized by bright-field optics. A Zeiss $20 \times$ long-working-distance objective was used to illuminate the specimens and monitor the photoreaction.

Confocal microscopy. Examination of the fluorescently labeled specimens was performed with a confocal microscope in order to obtain clear optical sections within the relatively thick tissue specimens. Three different scanning laser confocal microscope systems were employed. The first system was a Bio-Rad Microsciences MRC-500 that was extensively modified to improve photometric sensitivity (Smith et al., 1990). The Bio-Rad was used in conjunction with a Zeiss IM-35 that was equipped with a transmitted light detector (built by T. Ryan, Stanford), permitting simultaneous epifluorescence and Nomarski imaging. 
The second and third microscopes werc custom designed and built by S.JS. All microscopes were equipped with a $25 \mathrm{~mW}$ air-cooled argon ion laser for illumination. Microscope objectives used were a Nikon $20 \times(0.75 \mathrm{NA})$ and an oil-immersion Olympus DApo $40 \times(1.3 \mathrm{NA})$. For recording the images, the video output was sent from the microscope to an optical memory disk recorder (Panasonic TQ-2028F) and/or stored digitally on a network file server.

For time-lapse observation, living specimens were mounted in a closed chamber with about $0.5 \mathrm{ml}$ of culture media. Our observations indicated that metabolism by the brain slice necessitated replacement of the chamber media at least every $8-10 \mathrm{hr}$ during lengthy time-lapse sessions. Single images or Z-series stacks of images were collected at time intervals of 1-10 min. Since fibers located deep within the tissue slice had a somewhat tortuous course with respect to the optical section plane, typically only short segments of the axons were visible in single confocal image planes (1-2 $\mu \mathrm{m}$ focal depth). When stacks of confocal images were collected and combined to produce extended focus images, much longer segments of fibers could be visualized and growing fibers with tortuous paths could be better retained in focus. Thus, in some experiments multiple optical sections (five to seven images at $1-2 \mu \mathrm{m}$ steps) were collected in an automated fashion. This was accomplished by computer control of the focus via a stepper motor. The stacks of images were stored digitally and later recombined using a maximum-brightness operation to produce extended focus images.

Electron microscopy. Slices were fixed with $2 \%$ glutaraldehyde in 0.1 $\mathrm{M}$ cacodylate buffer for $30 \mathrm{~min}$ and postfixed in $0.5 \% \mathrm{OsO}_{4}$ containing potassium ferricyanide for $30 \mathrm{~min}$. Slices were rinsed, stained with $2 \%$ aqueous uranyl acetate (overnight), dehydrated in alcohol series, and embedded in Embcd 812 (Elcctron Microscopy Sciences). After hardening, thin sections were cut using a Reichardt Ultracut E. Sections were poststained with uranyl acetate and Sato's lead, and examined with a Philips 410 electron microscope at $60 \mathrm{keV}$ accelerating voltage.

Electrophysiology. Organotypic cultures (10-14 d old) were mounted on a Zeiss upright microscope and cells were visualized through a $40 \times$ water-immersion objective using a Newvicon video camera (Hamamatsu). The cultures were superfused with artificial cerebrospinal fluid (ACSF: $119 \mathrm{~mm} \mathrm{NaCl}, 2.5 \mathrm{~mm} \mathrm{KCl}, 1.3 \mathrm{~mm} \mathrm{MgSO}, 2.5 \mathrm{~mm} \mathrm{CaCl}$, $1.0 \mathrm{~mm} \mathrm{NaH} \mathrm{PO}_{4}, 26.2 \mathrm{~mm} \mathrm{NaHCO}_{3}$, and $11 \mathrm{~mm}$ glucose; $\mathrm{pH} 7.5$ ) saturated with $95 \% \mathrm{O}_{2}, 5 \% \mathrm{CO}_{2}$ at a rate of $1-2 \mathrm{ml} / \mathrm{min}$. All experiments were done at room temperature $\left(22-24^{\circ} \mathrm{C}\right)$. Whole cell recordings were made from CA3 pyramidal neurons using established techniques (Hamill et al., 1981; Blanton et al., 1989). Patch electrodes were pulled from micropipcttes (VWR 53432-921) using a multistage puller (Sutter Instruments) to a tip diameter of $1.5-2 \mu \mathrm{m}$ and filled with an internal solution containing $100 \mathrm{~mm} \mathrm{~K}$-gluconate, $10 \mathrm{~mm}$ EGTA, $5 \mathrm{~mm} \mathrm{MgCl}_{2}$, $40 \mathrm{~mm}$ HEPES, 2 mM ATP, $0.3 \mathrm{~mm}$ GTP, and $1 \mathrm{~mm}$ QX-314; $\mathrm{pH} 7.25$. Electrode resistance was 3-6 M . Whole-cell currents were recorded with an Axoclamp-2A (Axon Instruments), amplifier, low-pass filtered by an 8-pole Bessel filter (Frequency Devices Inc.), and digitized at $0.1-$ $10 \mathrm{kH}$ using custom data acquisition software written in Axobasic (Axon Instruments) by Dr. Daniel Madison (Stanford). Recordings were stable for $>4 \mathrm{hr}$. Series resistance effects were left uncompensated.

Puffer pipettes were made by breaking microelectrodes pulled from World Precision Instruments glass (1B100F-4) to a tip diameter of 2$5 \mu \mathrm{m}$. Pipettes were backfilled with $10 \mathrm{~mm}$ glutamate in ACSF. Local glutamate application to stimulate neural pathways in slice cultures (aftcr Bolz et al., 1992) was achieved by applying brief ( $50-500 \mathrm{msec}$ ) pressure pulses to the back of the pipette using a computer-controlled solenoid valve (General Valve Corp.) connected to compressed air at 10-30 psi. The recording electrode and puffer pipette were positioned with three-axis motorized micromanipulators (Zeiss), and the perfusion was adjusted so that the flow was always in the direction from CA3 to dentate to prevent diffusion of glutamate to CA3.

\section{Results}

MF giant synapses were examined in both acutely isolated and roller tube-cultured hippocampal slices. The acute slices were used to verify that SynI-immunostaining detects MF giant terminals in hippocampal slices, and to determine the normal pattern of staining. The distribution of giant synapses was then examined in normal cultured slices, and de novo MF synapse formation was assessed in slices cultured after lesioning of the MF tract. Finally, we used time-lapse confocal imaging of live acute or bricfly cultured slices to examine the dynamics of DiIor DiO-labeled MFs.

\section{Mossy fiber synapses in vivo}

\section{Detection of giant synapses with synapsin I antiserum}

Previous work had suggested that immunofluorescent staining with a polyclonal antiserum against Syn-I, a synaptic vesicleassociated protein (DeCamilli et al., 1983a,b), could be used to visualize synaptic boutons at the light microscope level (DeCamilli et al., 1983a; Fletcher et al., 1991). To characterize the appearance of anti-Syn-I-stained terminals in fixed and permeabilized but otherwise intact hippocampal slices, we immunostained acute slices en bloc and examined them with a scanning laser confocal microscope. As shown in Figure 1, confocal images revealed discernible fluorescent staining throughout all regions of the hippocampus. The granule cell layer in the DG and the pyramidal cell layer (stratum pyramidale; SP) in the hippocampal CA 1 and CA 3 subfields were distinguishable as bands of low immunoreactivity. The most intense immunoreactivity was found in the suprapyramidal layer (SL; also known as the stratum lucidum) of area CA3 (Fig. 1B), where MFs are known to course and form giant synaptic terminals (Blackstad and Kjaerheim, 1961). At higher magnification it was evident that the intense staining in the SL consisted of many large and distinct immunoreactive spots, or "puncta," some of which were several microns in diameter (Fig. 1C). The large puncta were almost entirely confined to the dentate hilar region and to the SL. A few large puncta and many smaller puncta were found within the SP. Small immunoreactive puncta were also highly concentrated in stratum radiatum (SR) and stratum oriens (SO), with a higher density of staining in the SO (Fig. $1 B$ ). Although small immunoreactive puncta were found throughout the slices, the distribution of large puncta corresponded precisely to the regions known to contain giant boutons of the MFs. Thus, whilc the Syn-I antiserum appears to label most or all mammalian CNS synapses (DeCamilli et al., 1983a,b), the mature MF terminals were distinguishable from other synaptic terminals in the hippocampus based on their large size and localization.

\section{Development of mossy fiber synapses in vivo}

To examine the normal development of MF terminals in vivo, acutely isolated hippocampal slices from P1-P1 1 rats were fixed and immunostained with the Syn-I antiserum. Confocal imaging showed that Syn-I immunoreactivity within the SL of area CA3 rapidly increased over the first postnatal week (Fig. 2). There was essentially no differentiation of the SL with regard to Syn-I staining at P1. The SL was distinct by $\mathrm{P} 4$, but immunoreactivity was diffuse, with only small puncta evident. However, at P8 the SL was well demarcated, intensely stained, and filled with many intermediate-sized and some large puncta. By P11 there were many large puncta within the SL, and at some septotemporal levels large puncta were also found within and just below the pyramidal cell layer (i.e., the intra- and infrapyramidal layers). Thus, the development of Syn-I immunoreactivity within the SL during the first postnatal week parallels the known time course of formation and maturation of MF giant synapses as assessed by electron microscopy (Bliss et al., 1974; Stirling and Bliss, 1978; Amaral and Dent, 1981). This provides further evidence for identification of the large Syn-I-immunoreactive puncta with the MF giant synapses. 

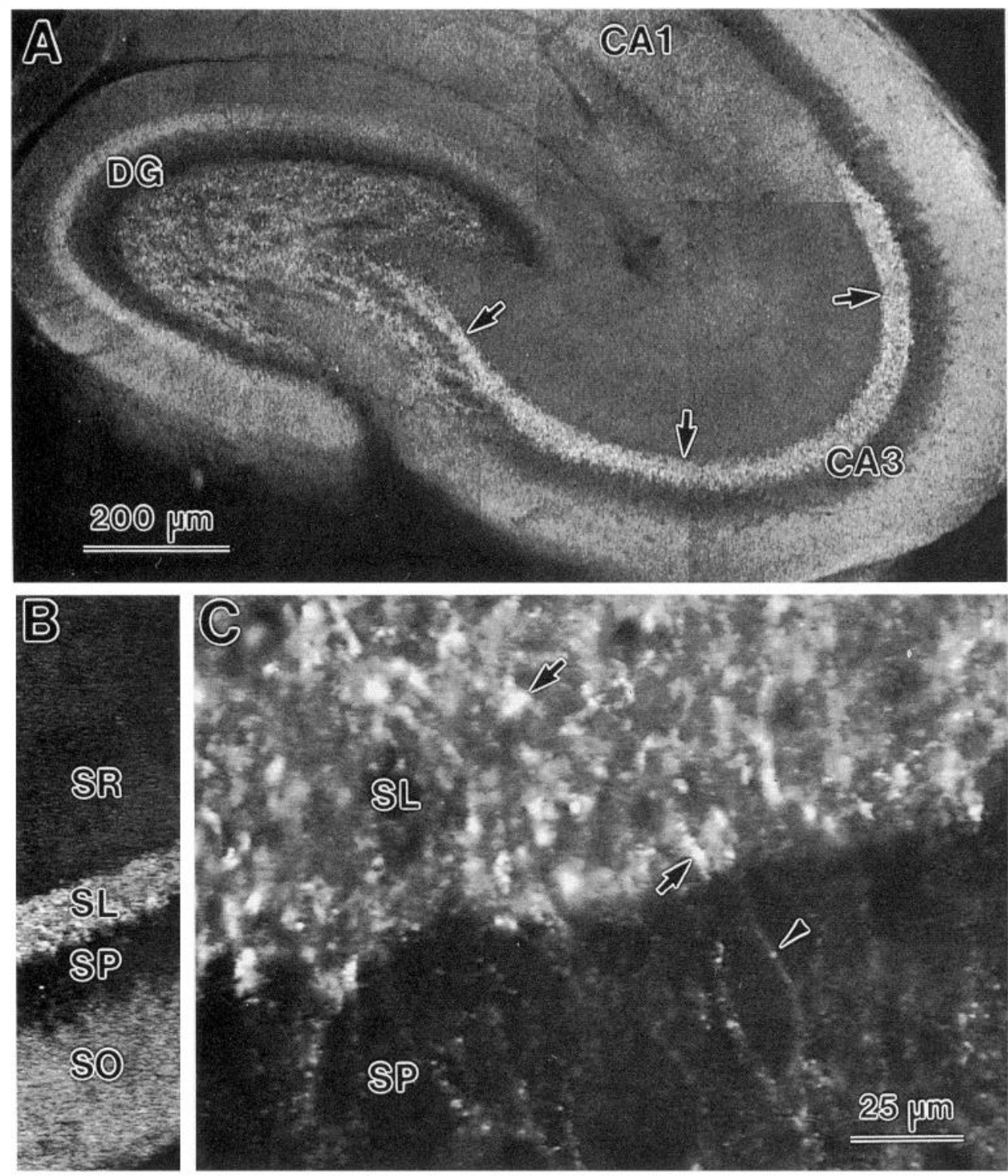

Figure 1. Staining of acute hippocampal slice with synapsin I antiserum. $A$, Low-magnification photomontage of a slice from a P13 rat. Intense immunoreactivity (arrows) corresponds to the SL of area CA3, where MFs elaborate giant synaptic terminals. $B$, Intermediate magnification image of CA3 showing the stratum radiatum $(S R)$, stratum lucidum or suprapyramidal layer $(S L)$, stratum pyramidal $(S P)$, and stratum oriens $(S O)$. $C$, Higher-magnification view of area CA3 showing only the $S L$ and $S P$. The $S L$ is packed with large Syn-I-immunoreactive "puncta" (arrows), which presumably correspond to individual giant MF terminals. The stratum pyramidale $(S P)$ at this septotemporal level is devoid of large puncta, but small puncta (arrowhead) are situated adjacent to pyramidal cell somata.

\section{Mossy fiber synapses in vitro}

Giant synapses in normal cultured slices

Organotypic culture methods (Gähwiler, 1981, 1984b) now provide an opportunity to study development of some CNS systems in vitro, but the degree to which each system develops normally needs to be thoroughly investigated. Some connections are lost during the tissue isolation procedure, and synaptic reorganization can occur in hippocampal slice cultures (e.g., Zimmer and Gähwiler, 1984; Frotscher and Gähwiler, 1988). Thus, we examined the distribution of giant MF terminals in organotypic slice cultures. Slices derived from P7 rat hippocampi were cultured for 2 weeks following the method of Gähwiler (1981, 1984b), and then fixed and immunostained with the Syn-I antiserum. We consistently found an intensely immunoreactive band of staining along the superficial aspect of the CA3 pyramidal cell layer (Fig. 3), which corresponds to the SL. At higher magnification, it was evident that small fluorescent puncta were scattered throughout the SR, SO, and SP, but that the intensely immunoreactive SL consisted of many large fluorescent puncta (Fig. 4A). These large, irregularly shaped puncta were situated directly adjacent to apical dendrites of pyramidal neurons, which is consistent with the distribution of MF giant boutons in vivo. The large puncta were invariably located in the dentate hilus and area CA3, but never in area CA1. Thus, the distribution of large Syn-I-immunoreactive puncta in 2-week-old organotypic cultures was similar to that of acutely isolated slices, though they were found at a somewhat lower density.

\section{Absence of giant synapses in slices cultured without the dentate}

To test further whether the large Syn-I-immunoreactive puncta correspond to MF terminals, and to determine whether Syn-I staining of synaptic sites persists after lesioning of MFs, the DG (i.e., the source of MFs) was extirpated from hippocampal slices at the beginning of the culture period (Zimmer and Gähwiler, 1987). After 2 weeks in culture, the slices were fixed and stained with the Syn-I antiserum. Comparison of slices cultured with or without the DG indicated that the density of small immunoreactive puncta in area CA3 was qualitatively comparable under both culture conditions, but there were few if any large puncta in CA3 of slices cultured without the DG (Fig. 4). Thus, 

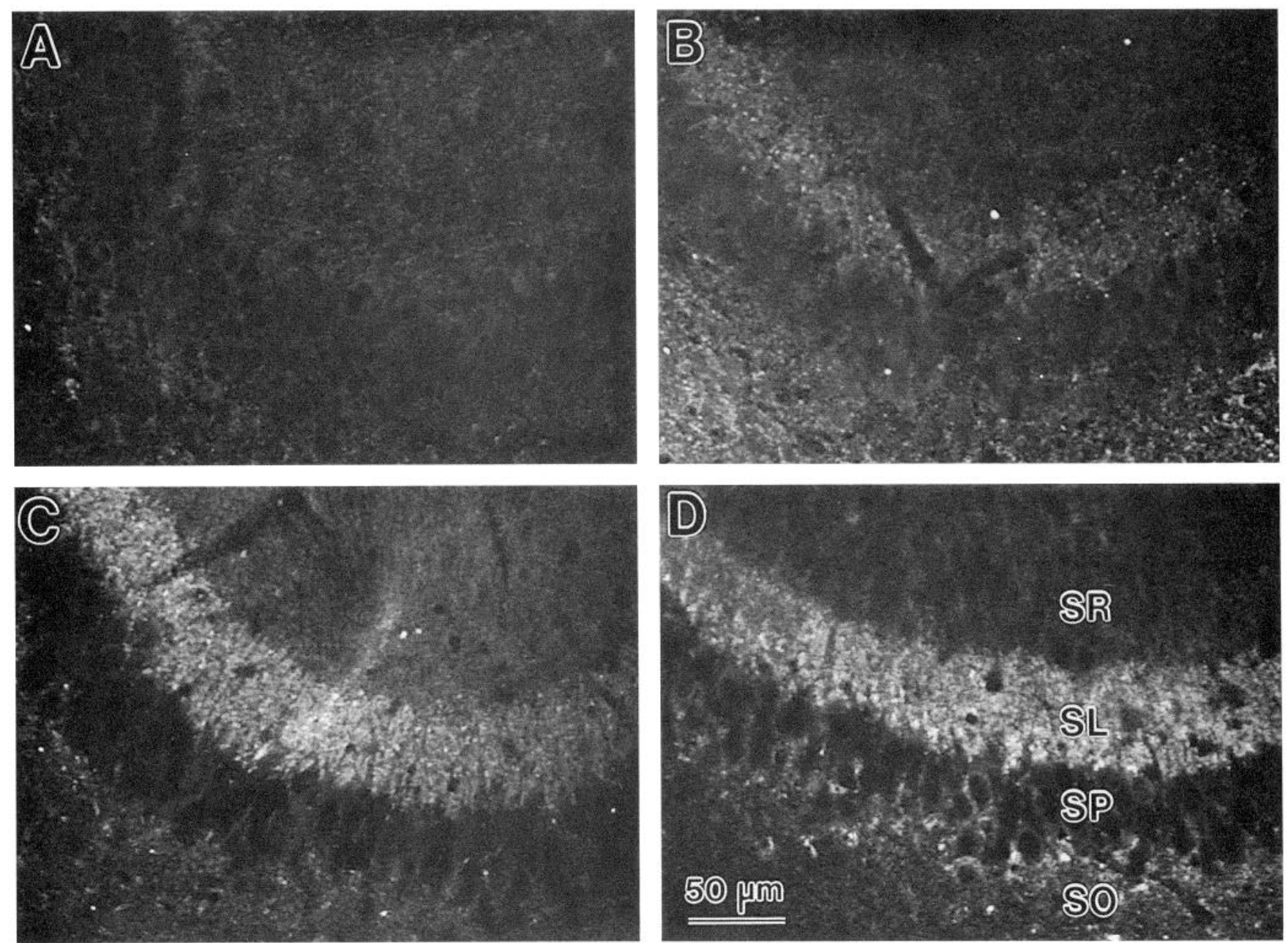

Figure 2. Development of MF synapses in vivo shown by Syn-I immunostaining of acute hippocampal slices from different aged rats. $A$, Pl. B, P4. $C$, P8. D, P11. These images of area CA3 show the progressive accumulation of Syn-I immunoreactivity in the SL, which corresponds to the zone of MF terminals, over the first postnatal week. Slices from each age were fixed and processed in parallel, and imaging was performed under identical conditions.

removal of the source of MFs also eliminated the large immunoreactive puncta. This is strong evidence that these large puncta correspond to the MF terminals. It should be emphasized that large puncta were not observed in slices cultured without the DG even though some giant synapses were probably already present at P7 when the slices were prepared for culture (see Fig. 2 ). Thus, removal of the DG prior to culturing slices likely resulted in complete degeneration of extant MF terminals in area CA3.

\section{Ultrastructure of giant synapses in cultured slices}

To determine the ultrastructural correlate of the large immunoreactive puncta in area CA3, 2-week-old organotypic slice cultures were examined by thin section electron microscopy. Giant synaptic terminals ( $>2 \mu \mathrm{m}$ diameter) containing large clusters of clear synaptic vesicles were found along the apical dendrites of CA3 pyramidal neurons, primarily in the SL and superficial region of the SP (Fig. 5). A few giant terminals were also found deeper within the SP, but they were not seen outside the SL and SP of area CA3. Giant terminals typically made several symmetrical contacts (nonsynaptic desmosome-like junctions, or puncta adherentia) with dendritic shafts of pyra- midal cells, and asymmetrical synaptic contacts with dendritic spines. Rarely did the giant terminals form synaptic junctions with the somata of pyramidal cells, although small $(<2 \mu \mathrm{m}$ diameter) boutons were observed to contact somata synaptically. The overall appearance of the giant terminals was similar to that observed by others in organotypically cultured hippocampal slices (Zimmer and Gähwiler, 1984; Frotscher and Gähwiler, 1988). These results indicate that giant MF-like synapses are present in 2-week-old organotypic cultures, and it is very likely that the large Syn-I-immunoreactive puncta correspond to these giant synaptic terminals.

\section{Mossy fiber growth and synapse formation after a lesion}

\section{Growth of mossy fibers in cultured slices after lesioning}

We wanted to determine if MFs grow and form new synaptic connections in isolated hippocampal slices, but it is problematic to distinguish retrospectively between synapses formed in vitro from those formed in vivo (i.e., prior to the culturing procedure). By P5-P7, when hippocampal tissue can be suitably maintained in slice culture, some MFs have already made immature synaptic contacts with CA3 pyramidal neurons (see Fig. 2; see also 


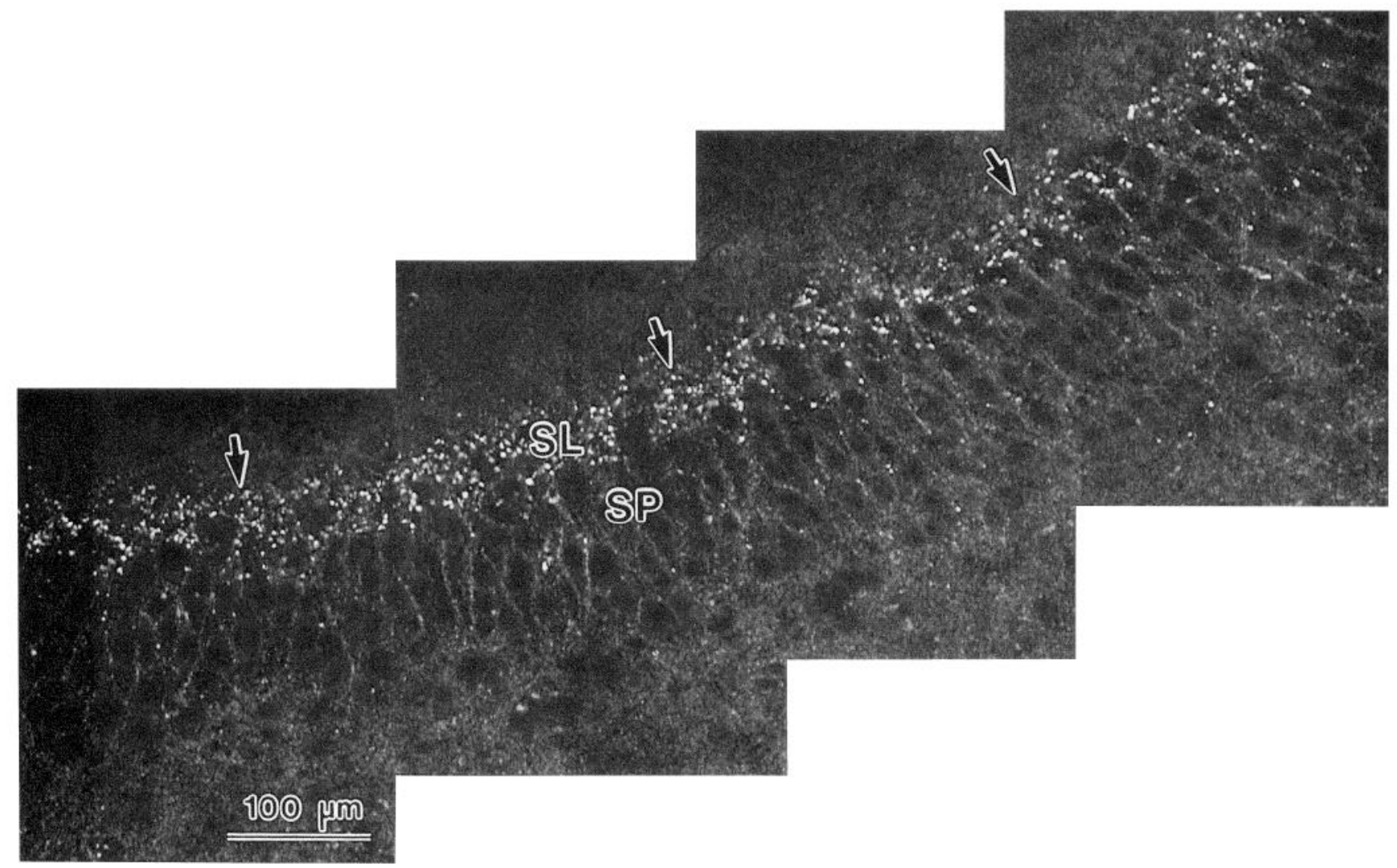

Figure 3. Confocal photomontage showing pattern of Syn-I staining in area CA3 of a "normal" 2-week-old organotypic slice culture (P7, $14 \mathrm{~d}$ in vitro). The pyramidal cell layer $(S P)$ is conspicuous because the cell somata (especially the nuclei) are unstained and appear dark in relief. Large fluorescent puncta occupy the suprapyramidal layer ( $S L$, arrows), a narrow strip along the apical dendrites of CA3 pyramidal neurons. The distribution of large puncta is similar in the cultured and acutely isolated tissue, although the density is somewhat reduced in the cultured tissue.

Stirling and Bliss, 1978; Zimmer, 1978; Amaral and Dent, 1981). Thus, the emergence of giant synapses in normal organotypic cultures may have occurred by maturation of existing synaptic terminals formed prior to the culture period, before the tissue was removed from the brain. To investigate the potential of MFs to grow and exhibit all stages of synapse formation in vitro, we lesioned the MF pathway before culturing the slices. This should cause extant MFs and their terminals distal to the lesion to degenerate (see Fig. $4 B$ ) but not prevent outgrowth of new MFs. The lesion was made near the dentate, approximately onethird of the way along the normal MF pathway (Fig. 6A).

Growth of MFs following transections was examined by labeling fibers with a fluorescent lipophilic dye, $\mathrm{DiIC}_{18}(3)$ (DiI; Honig and Hume, 1986). Injections of DiI into the dentate hilus (Fig. $6 B$ ) resulted in a rather selective labeling of fiber bundles within the SL, which corresponds to the MF tract. Sometimes the intra- and infrapyramidal bundles in proximal CA3, which also contain MFs, were labeled (Fig. 6C). Dye injections into the dentate following transection of the MF tract revealed that labeled fibers within the SL initially extended only up to the lesion, but fibers subsequently traversed the lesion and extended more distally within CA3 (Fig. 6D). In most cultures, fibers that crossed the lesion were not confined to the SL on the distal side, but instead also extended into the adjacent SR and SP. Thus, labeled fibers radiated from the cut end of the MF tract, especially when the hippocampal laminae were not precisely aligned at the lesion. However, in a few cultures, fibers were highly concentrated within the SL on the distal side of the lesion (Fig.
7). This was observed when the laminae on both sides of the lesion were aligned and contiguous.

\section{Formation of giant synapses in cultured slices after lesioning}

By 2 weeks in vitro, dye-labeled fibers that crossed the lesion had elaborated large (2-5 $\mu \mathrm{m}$ diameter) en passant varicosities within the SL and SP of area CA3. Long (up to $15 \mu \mathrm{m}$ ) filopodial protrusions sometimes emanated from these varicosities (Fig. 8). The morphological features of these elaborate en passant varicosities are strikingly similar to those of MFs in vivo (e.g., Blackstad and Kjaerheim, 1961; Amaral, 1979; Amaral and Dent, 1981; Claiborne et al., 1986), suggesting that these DiIlabeled varicosities (like the large Syn-I puncta) correspond to MF giant terminals.

To determine if new giant synaptic boutons were formed distal to the lesion, we examined the pattern of Syn-I immunostaining in cultures 2 weeks after lesioning of the MFs. Low-magnification confocal images always clearly revealed the lesion site, which was evidenced as a disruption of the SP. At higher magnification, many large Syn-I-immunoreactive puncta were found in the SP on both the proximal (dentate) and distal sides of the lesion (Fig. 9). The large puncta on the distal side of the lesion likely arose from MFs, and not local neurons, since these puncta were not found when the granule cells were removed when severing the MF tract (see Fig. 4). The concentration of large puncta on the distal side of the lesion was always highest in the region directly adjacent to the lesion, and the density of large puncta tapered off more distally toward CA1 (Fig. 9). The large 

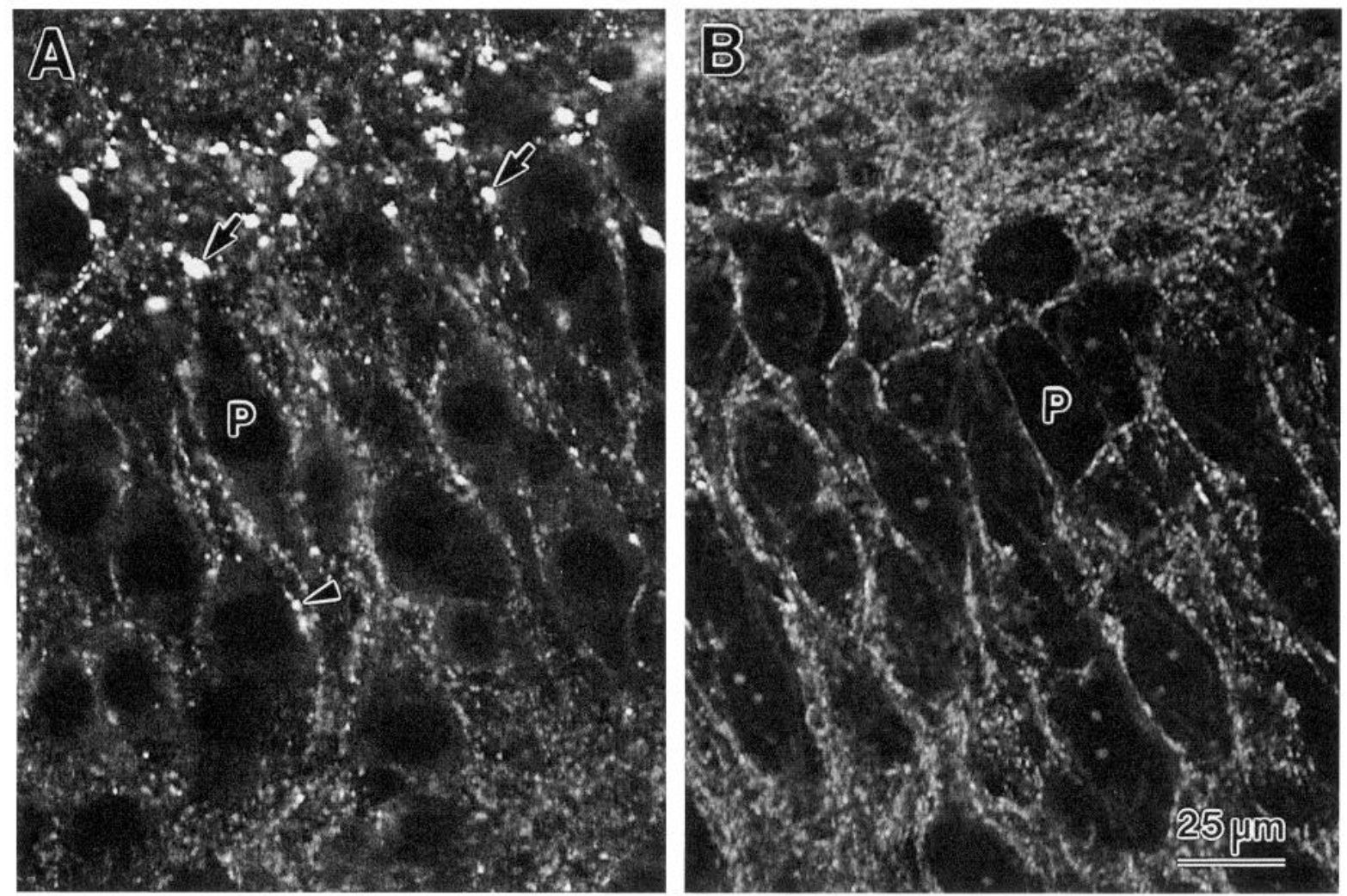

Figure 4. Higher magnification confocal images of Syn-I staining in 2-week-old organotypic slices $(\mathrm{P} 7,14 \mathrm{~d}$ in vitro) cultured with $(A)$ or without $(B)$ the dentate gyrus. $A$, Several large puncta (arrows) reside along the apical dendrites of pyramidal cells $(P)$ when the dentate granule cells are retained in the culture. Small fluorescent puncta (arrowhead) are found adjacent to pyramidal cell somata and throughout the slice. $B$, Large Syn-I puncta are missing when the dentate is removed prior to culturing the slices. This strongly supports the idea that large puncta correspond to MF boutons. Note that a similar distribution and density of small puncta are found under both culture conditions.

puncta were not strictly confined to the SL and superficial region of the SP, as in the normal cultures (see Fig. 3), but instead were more widely scattered throughout the SP. This dispersion within the SP was evident on both sides of the lesion. Nonetheless, in most cultures there appeared to be a slightly higher concentration of large puncta in the SL relative to the SP, especially at more distal locations in CA3.

Because the large Syn-I-immunoreactive puncta distal to the lesion were dispersed more widely than normal within the SP, we were interested to know whether these giant synapses that had formed in vitro had lost their normal specificity for apical dendrites of pyramidal cells. Conceivably, the giant synapses that were dispersed within the SP could be associated with pyramidal cell somata or with the apical dendrites of cells situated deep within the SP, near the SO. To address this question, we examined regions of slices distal to the lesion by electron $\mathrm{mi}$ croscopy. Many large ( $>2 \mu \mathrm{m}$ in diameter) synapses were found on the distal side of the lesion within both the Sl and the SP (Fig. 10). These giant synaptic terminals had a similar appearance to those observed in normal cultures, containing many clear vesicles and some dense-core vesicles. In addition, they had symmetrical junctions in association with dendritic shafts of pyramidal cells, and made multiple asymmetrical synaptic junctions with dendritic spines. As in normal cultures, but unlike terminals found in vivo, we did not see dendritic elements perforating the presynaptic terminals. Although some of the giant terminals were situated near pyramidal cell bodies, all of the synaptic junctions ( $n=22$ terminals) were formed with dendritic shafts or complex spines rather than with pyramidal cell somata (Fig. 10C). Together, the results indicate that MFs in slice cultures elaborate new synaptic terminals with morphological features similar to those found in nonlesioned organotypic slices, and the new MF contacts in cultured slices are formed selectively with dendritic domains of normal target cells.

\section{Reestablishment of excitatory synaptic input from dentate to CA3}

If functional MF connections were reestablished with CA3 pyramidal cells in culture after a lesion, we would expect stimulation of dentate granule cells to produce excitatory synaptic responses in pyramidal cells. To test this, granule cells in 2-weekold lesioned cultures were stimulated using a bipolar field elec-

Figure 5. Electron micrographs from normal organotypic slice cultures $(\mathrm{P} 7,14 \mathrm{~d}$ in vitro) showing giant MF synapses in the SL $(A, B)$ and SP $(C)$ of area CA3. A, Giant ( $>2 \mu \mathrm{m}$ in diameter) presynaptic terminals contain many clear vesicles and form symmetrical junctional contacts (puncta adherentia, arrows) along apical dendritic shafts $(D)$ of pyramidal cells. $B$, Asymmetrical synaptic contacts (arrowheads) are formed primarily with dendritic spines $(S)$. In a different plane of section, this same terminal was seen to make symmetrical contacts with an apical dendrite shaft. $C$, Although most giant terminals in normal slice cultures are found in the SL, some are also found in the superficial regions of the SP. Giant terminals (asterisks) in the SP form synaptic contacts with dendritic shafts or spines $(s)$ of pyramidal cells but rarely with pyramidal cell somata $(P)$. 


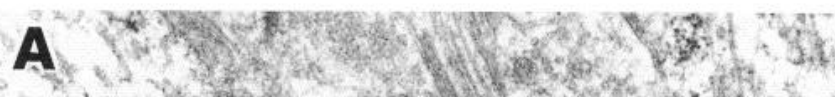

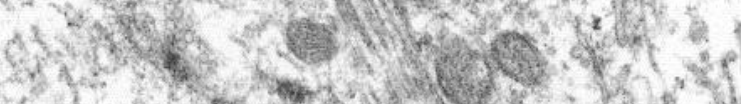

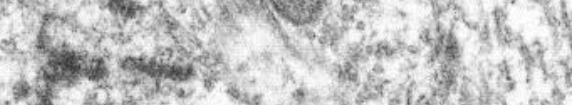

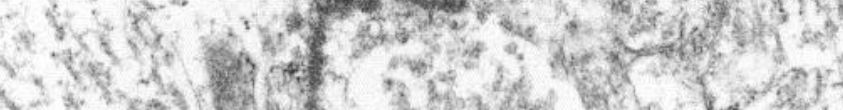

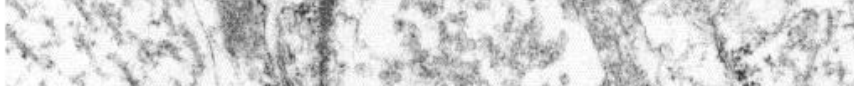

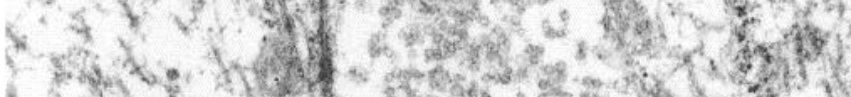

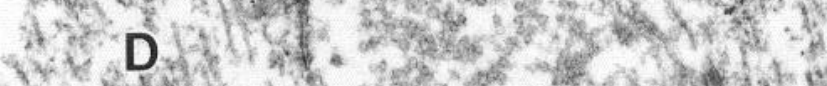

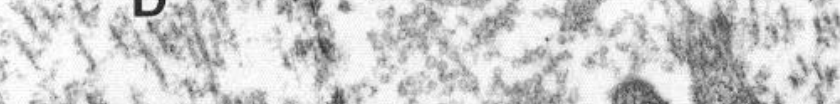

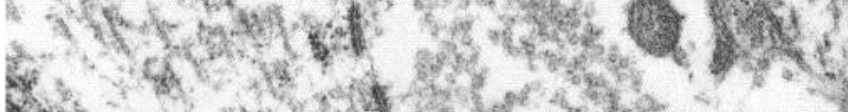
$x+100,10$ $1+1+10$

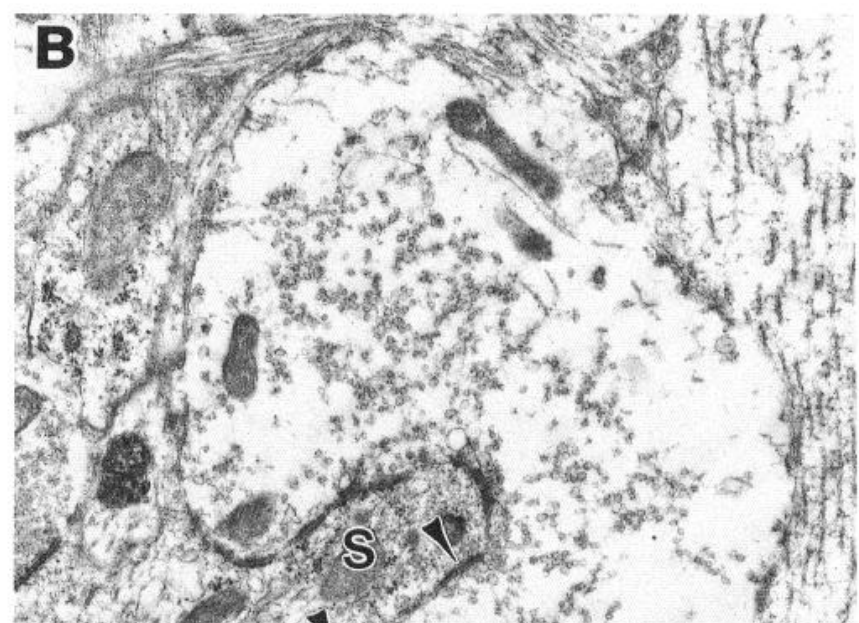

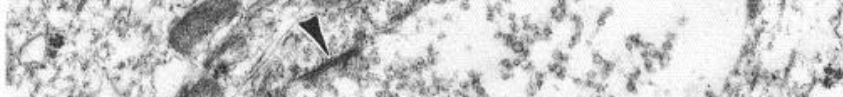

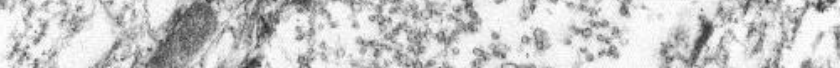

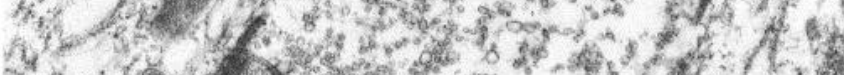

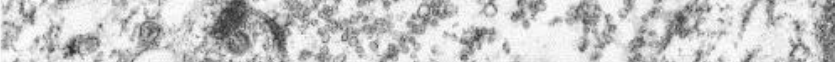

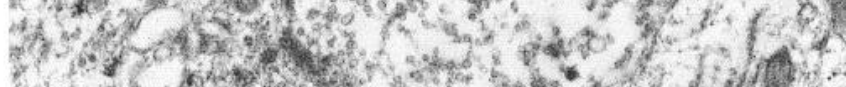

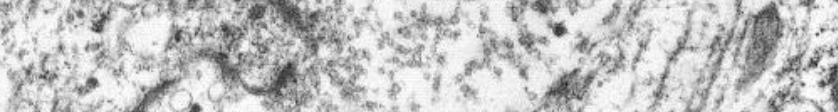

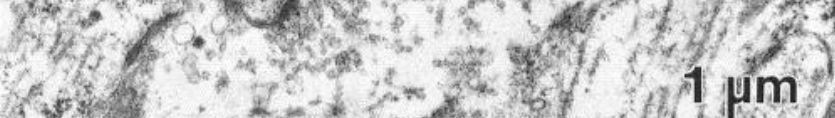

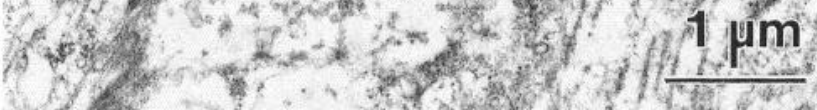

C.

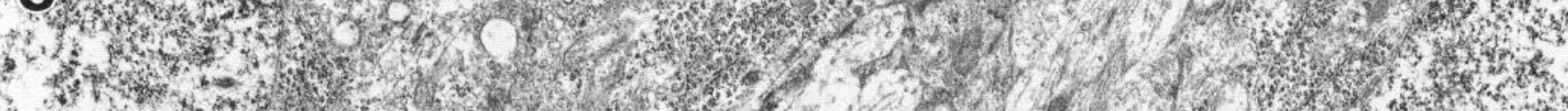

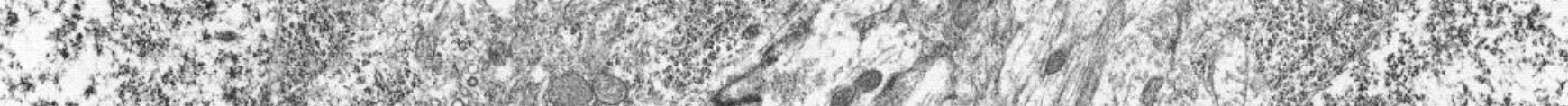

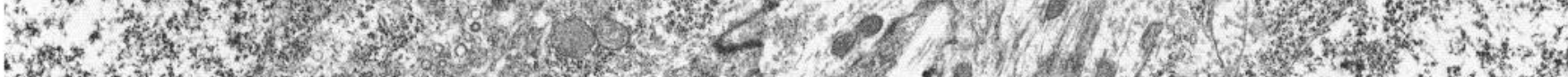

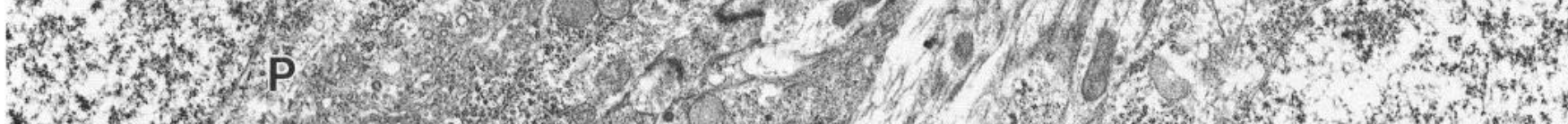
* 6. 150
6

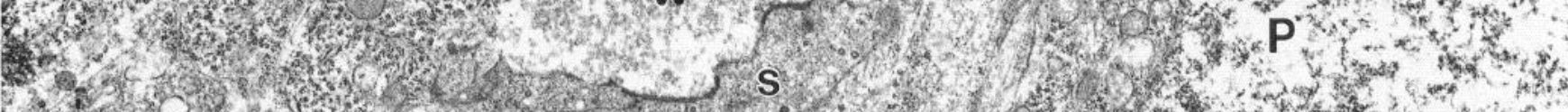

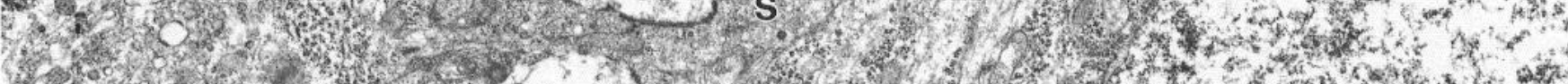

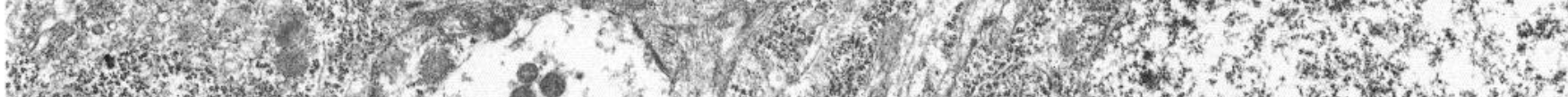

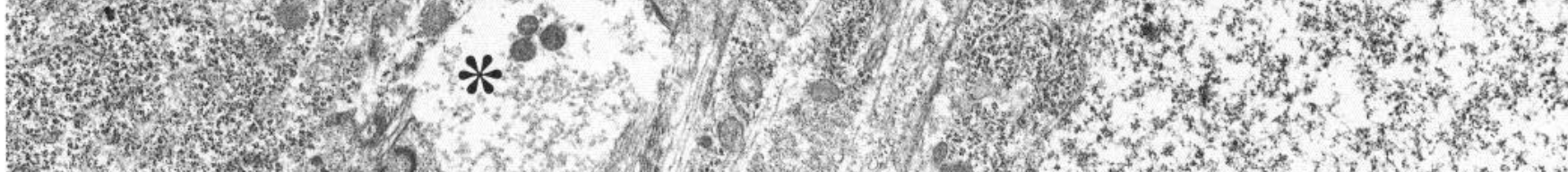

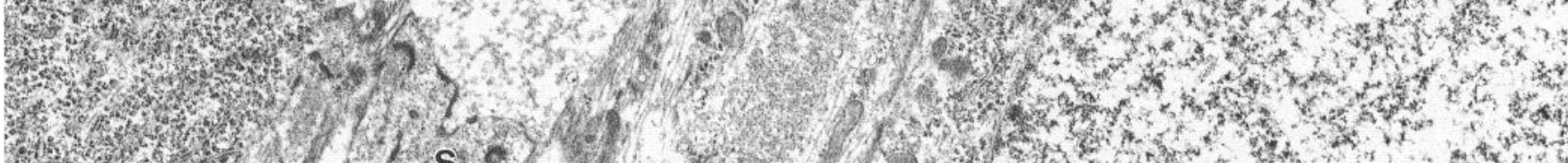

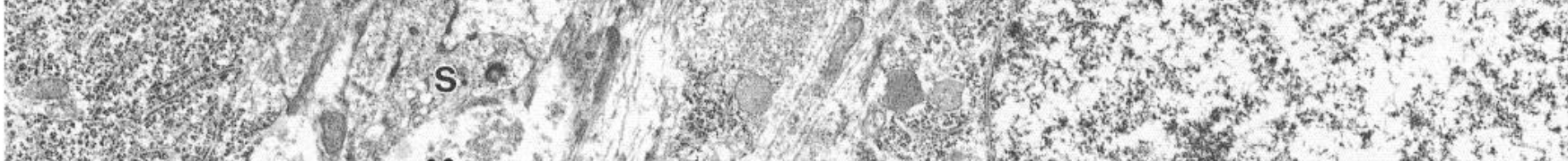

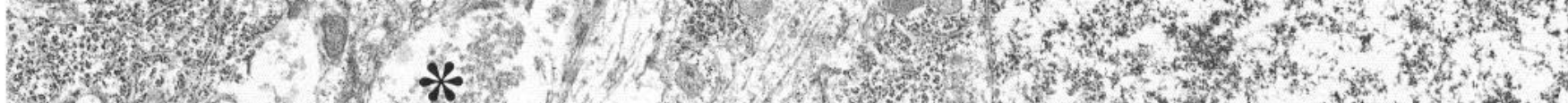

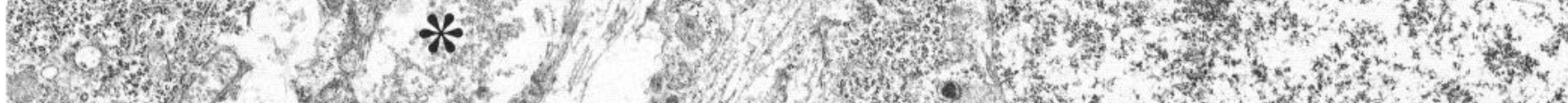

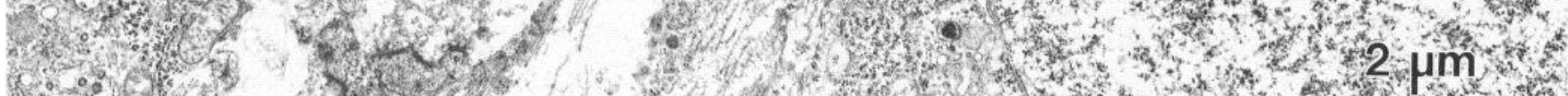

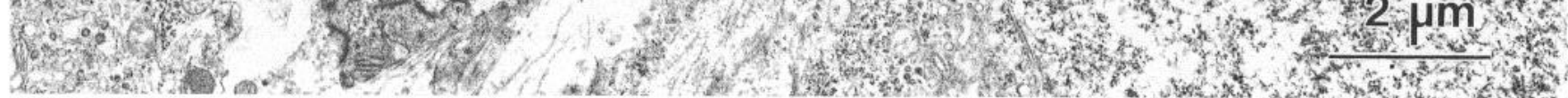



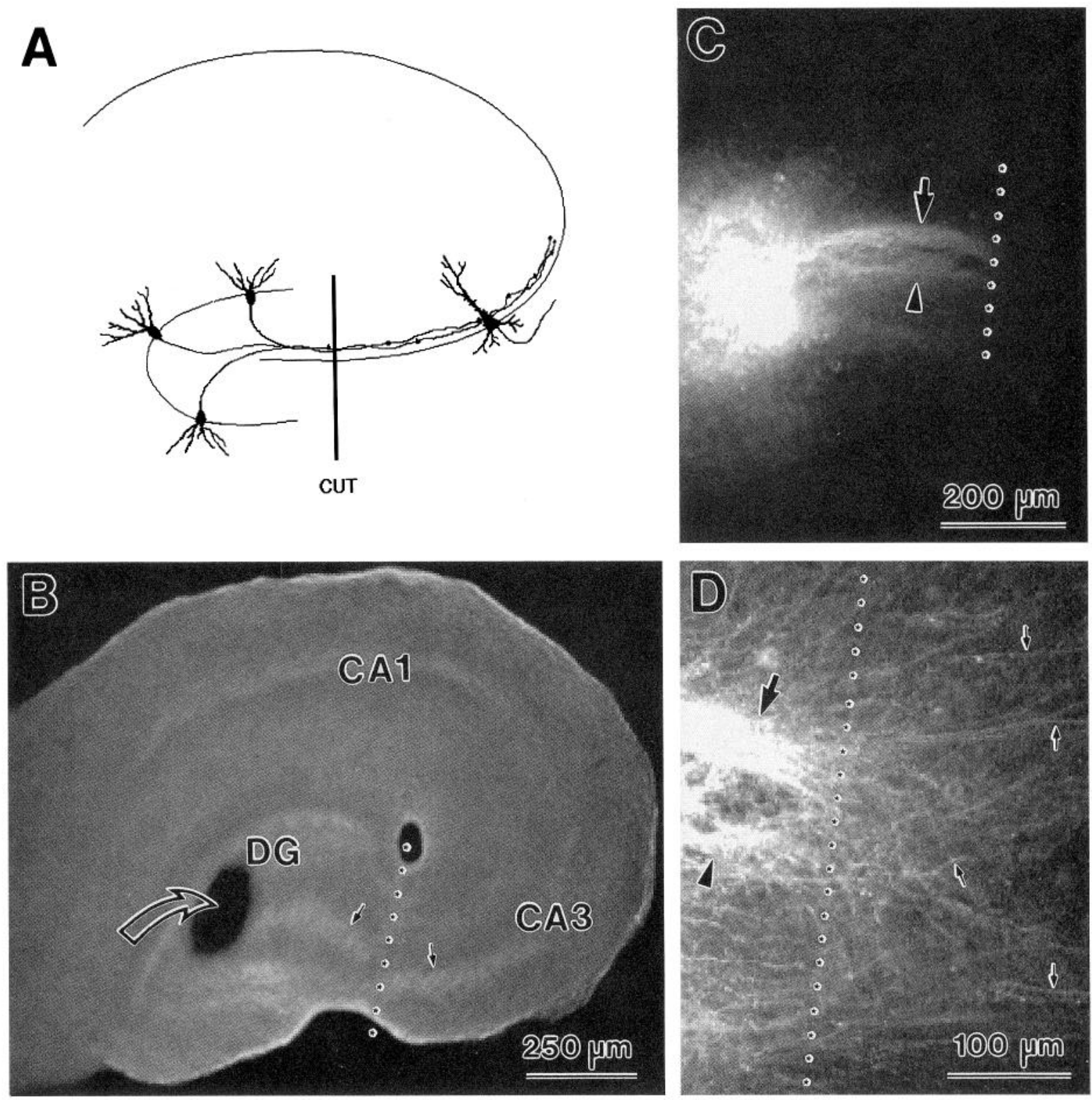

Figure 6. Lesioning of MF tract in slices before culturing. A, Schematic diagram showing the organization of the MF system and the location of the lesion of the MF tract. The MFs extend from granule cells in the DG to contact pyramidal cells synaptically in CA3. Lesioning of MFs (vertical line) should cause MFs and their synapses on the distal (right) side of the lesion to degenerate, but not prevent new growth of MFs back across the lesion into CA3. B, Bright-field image of an MF-lesioned slice $2 \mathrm{~d}$ after transection (P7, $2 \mathrm{~d}$ in vitro). The MF tract was transected (starred line) at the beginning of the culture period, but the cut stumps have reannealed. Note the slight displacement of the pyramidal cell layer (small arrows) at the lesion. DiI was injected into the dentate (open arrow) to label the MFs. C, Low-magnification fluorescence image shows labeling of MFs (arrow) up to the lesion (starred line). Both suprapyramidal (arrow) and infrapyramidal (arrowhead) MF tracts are labeled in this slice. $D$, Higher-magnification confocal image shows that a few DiI-labeled fibers (small arrows) have crossed the lesion (starred line) at this early stage (P7, $2 \mathrm{~d}$ in vitro). In most slices, fibers on the distal side of the lesion are not confined to the SL but instead invade several different laminae.

trode, and field recordings were made from the SP on the opposite (distal) side of the lesion in CA3. Electrical stimulation of the DG produced excitatory responses in CA3 that were blocked by TTX $(1 \mu \mathrm{M})$ or glutamate receptor antagonists [50 $\mu \mathrm{M}$ 6-cyano-7-nitroquinoxaline-2,3-dione (CNQX) $+10 \mu \mathrm{M}$ aminophosphonovalerate (APV)] in the bath (not shown). Although this is consistent with MF excitation of pyramidal cells, such responses could also have resulted from antidromic stimulation of CA3 neurons (via glutamatergic recurrent input from neighboring pyramidal cells) if some of the pyramidal cell axons inappropriately extended to the DG (as is known to occur in some organotypic culture conditions; Frotscher and Gähwiler, 1988). Thus, using electrical stimulation, we could not determine with absolute certainty whether the responses in pyramidal cells were due to direct antidromic stimulation via pyramidal cell axons or orthodromic stimulation via the MFs.

To avoid antidromic excitation of CA3 pyramidal neurons, we stimulated the dentate granule cells with local application of glutamate (Fig. 11A), a neurotransmitter excitatory to the granule cells (White et al., 1977). Glutamate application at the DG should depolarize the granule cells, activating the MF pathway, but should not antidromically excite pyramidal cell axons. 

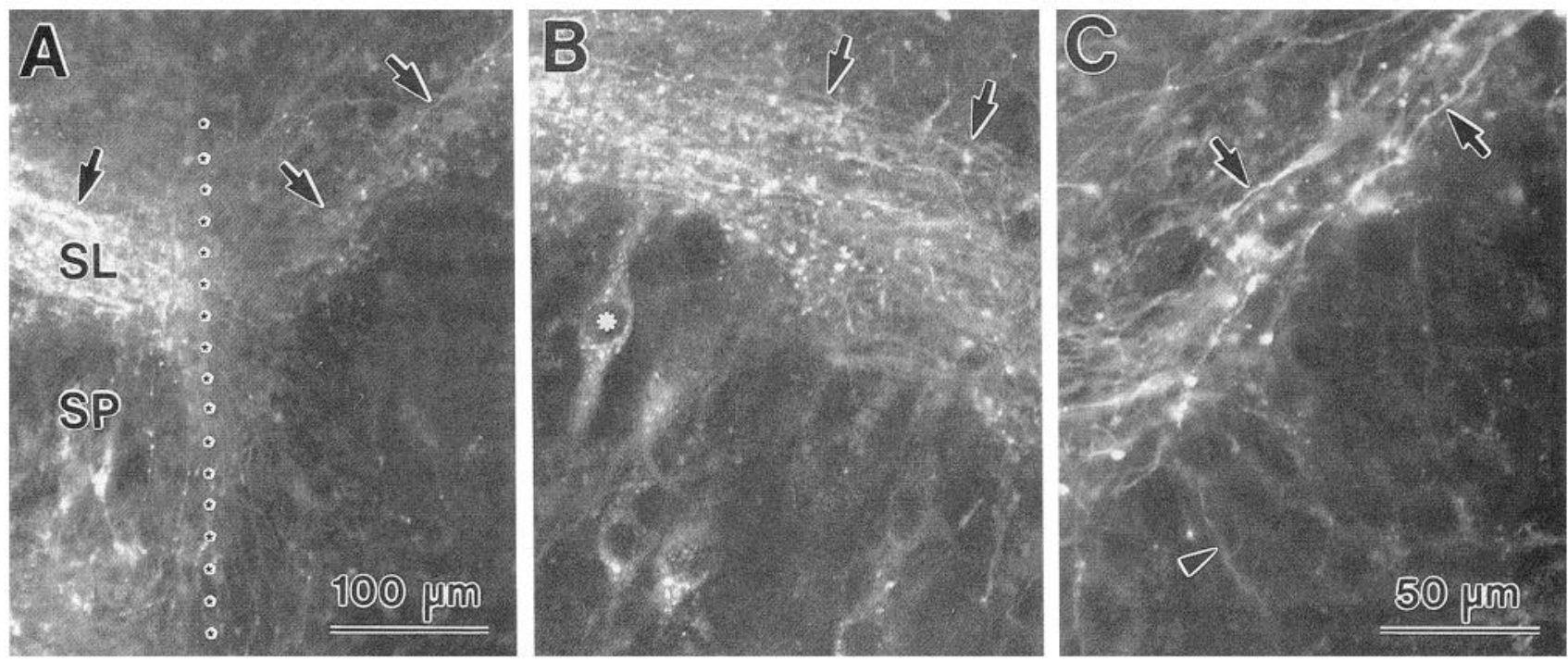

Figure 7. DiI-labeled MFs in a slice cultured for $6 \mathrm{~d}$ after lesioning of MF tract (P7, $6 \mathrm{~d}$ in vitro). In this slice, many growing MFs occupy their normal suprapyramidal position (arrows) on the distal side of the lesion. $A$, Confocal fluorescence image of labeled fibers at the lesion (starred line). The dentate is to the left. Although the pyramidal $(S P)$ and suprapyramidal layers $(S L)$ are contiguous at the lesion, the laminae in the proximal and distal stumps are oriented at oblique angles. $B$, Higher-magnification image of labeled fibers on the proximal (left) side of the lesion. Note the bundle of labeled fibers (arrows) within the SL, which is the normal pathway of MFs. Some pyramidal cells (asterisk) on the proximal side were back-labeled. $C$, High-magnification confocal image of labeled fibers on the distal (right) side of the lesion. Within this slice many fibers (arrows) on the distal side of the lesion were located within the SL. A few fibers (arrowhead) descend into the pyramidal cell layer. Individual fibers were seen to have originated from the proximal side of the lesion. Scale bar in $C$ also applies to $B$.
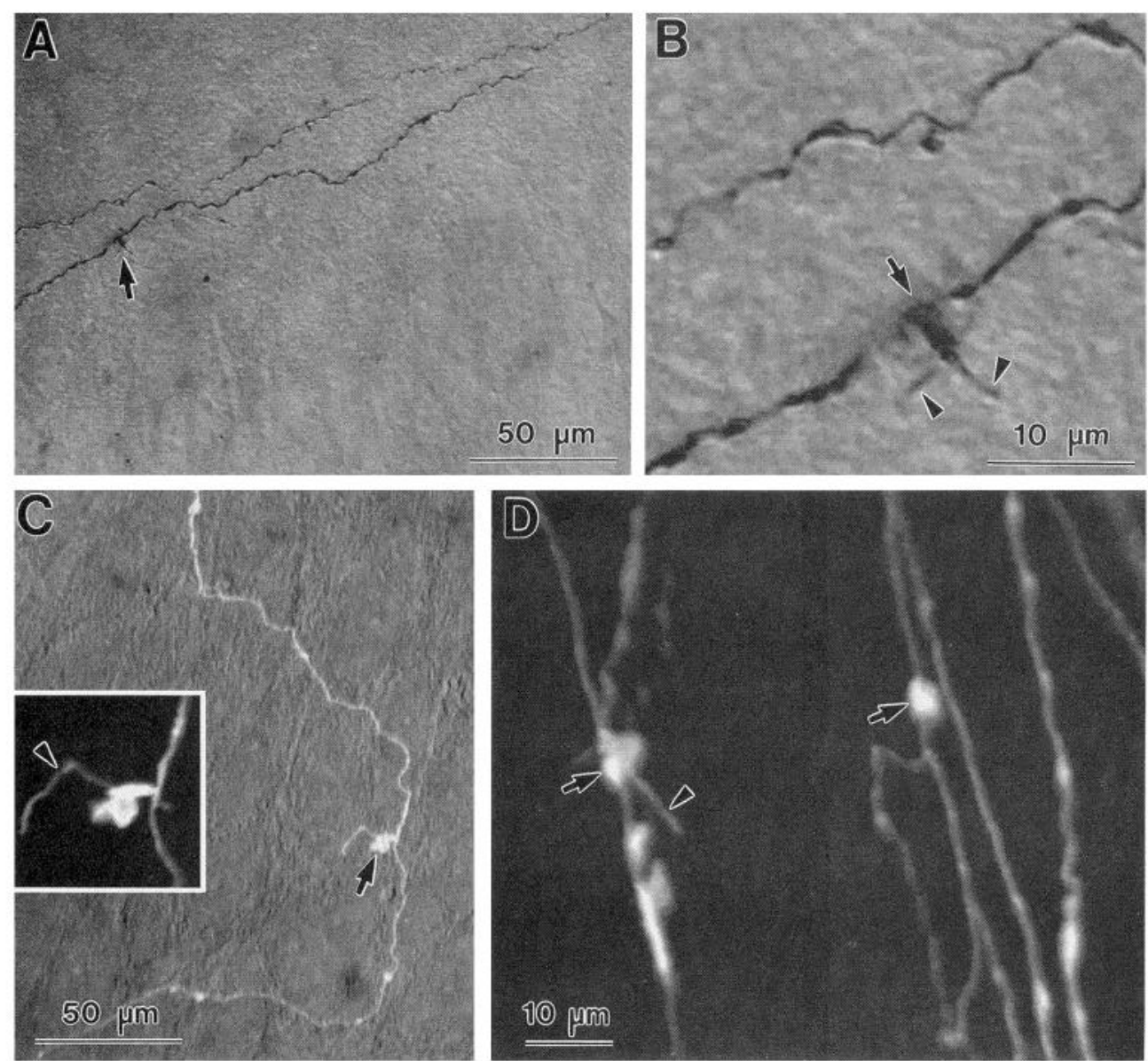

Figure 8. DiI-labeled fibers in area CA3 of 2-week-old MF-lesioned slices (P7, $14 \mathrm{~d}$ in vitro). These fibers were located on the distal side of the lesion and were anterogradely labeled by $\mathrm{DiI}$ application to the dentate gyrus. After crossing the lesion, some fibers course along the $\operatorname{SL}(A, B)$ while others descend into the pyramidal cell layer $(C, D) . A$, Nomarski image of two DiI-labeled fibers in area $\mathrm{CA} 3$ that course within the SL. One of the fibers elaborates a large varicosity (arrow). The DiI was photoconverted to produce a dark reaction product. $B$, Higher-magnification view of fibers and varicosity in $A$. Note the filopodia-like extensions (arrowheads) that project from the varicosity (arrow). $C$, A single fluorescently labeled fiber superimposed on a Nomarski image of the same field. The fiber originated from the dentate gyrus and extended into the CA3 pyramidal layer, where it elaborated a large en passant varicosity (arrow). Inset is higher-magnification view of the varicosity without the Nomarski background. A single filopodia-like process (arrowhead) is seen to emerge from the varicosity. $D$, Different slice showing several DiI-labeled fibers that descended into the pyramidal layer near the lesion. Some of the fibers have large varicosities (arrows), which occasionally have filopodia-like extensions ( $a r$ rowhead). These large en passant varicosities with filopodia-like extensions are very similar to varicosities of MFs in vivo. 


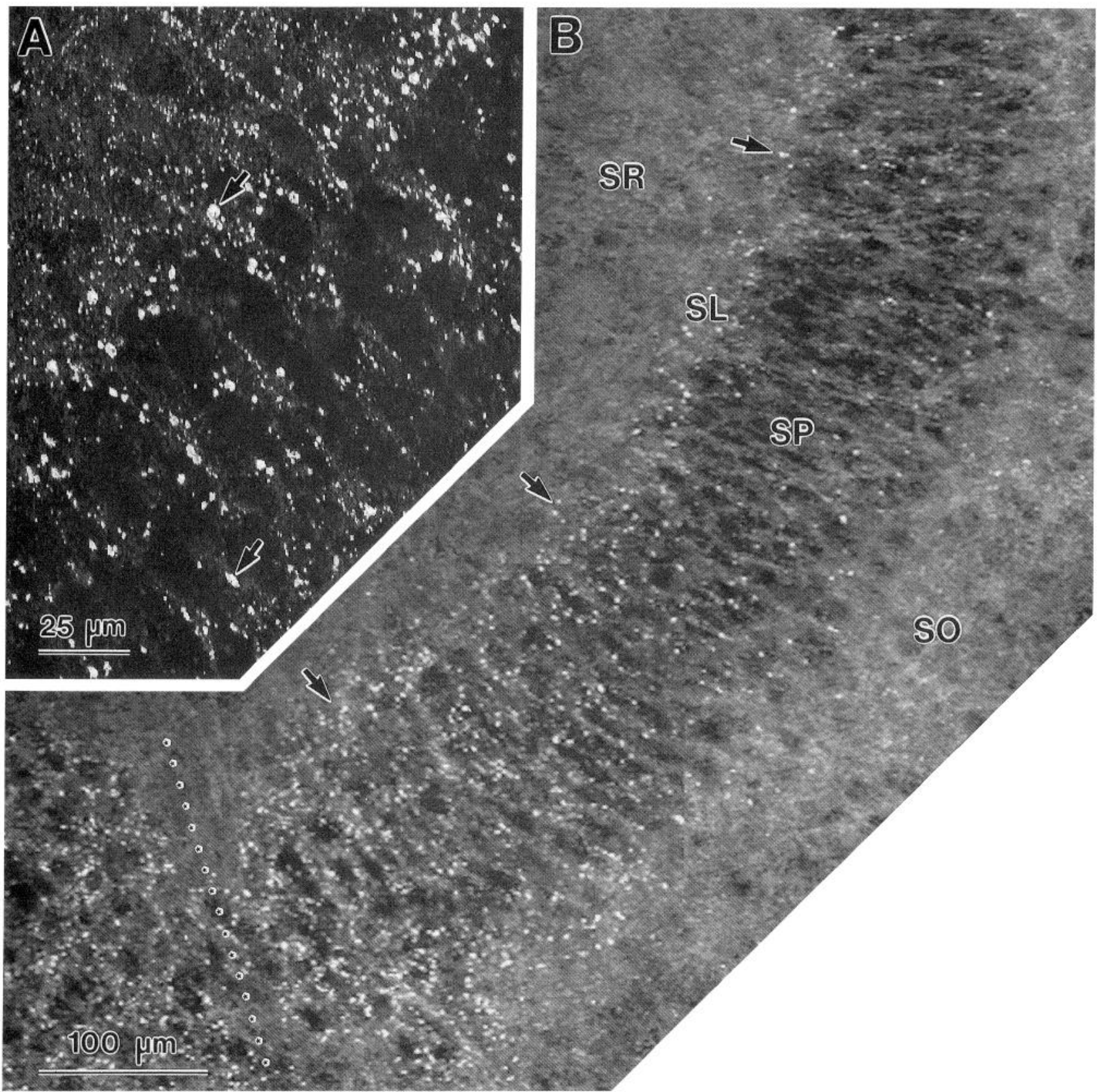

Figure 9. Syn-I immunostaining of an MF-lesioned organotypic slice after 2 weeks in culture (P7, $14 \mathrm{~d}$ in vitro). A, High-magnification confocal image in area CA3 distal to the lesion. Note that large puncta (arrows) are found within and adjacent to the pyramidal cell layer. $B$, Low-magnification confocal photomontage shows overall distribution of giant synapses relative to the lesion site (starred line). Dentate is to the left. Note the many large immunoreactive puncta dispersed throughout the CA3 pyramidal cell layer $(S P)$ on both the proximal and distal sides of the lesion. Giant puncta are found in the $S L$ and superficial regions of the $S P$ (arrows) more than $500 \mu \mathrm{m}$ distal to the lesion.

Glutamate (10 mM) was puffed onto granule cells in both normal organotypic slices and slice cultures where the MF tract had been lesioned 10-14 d earlier, and responses were recorded in CA3 pyramidal cells using the whole-cell voltage-clamp config- uration. In both normal and MF-lesioned slices, brief glutamate applications reproducibly induced in CA3 pyramidal neurons $(n=7)$ inward, excitatory synaptic currents that ranged from $50 \mathrm{pA}$ to about $1 \mathrm{nA}($ Fig. $11 B$ ). The responses were totally and

Figure 10. Electron micrographs showing giant synaptic terminals in slices cultured for 2 weeks after MF lesion (P7, $14 \mathrm{~d}$ in vitro). Giant synapses were found in the SL $(A, B)$ and SP $(C)$ of area CA3 distal to the lesion. $A$ and $B$. Presynaptic terminals make multiple symmetrical junctions (arrows) with dendritic shafts $(D)$ and asymmetrical synaptic junctions (arrowheads) with dendritic spines (s) of pyramidal cells. $C$, Giant terminals (asterisks) in the pyramidal cell layer formed synaptic junctions (arrowheads) with dendritic shafts and spines (s), but not with pyramidal cell somata $(P)$. These giant synapses, which were formed de novo in culture, are morphologically similar those in nonlesioned organotypic slices (compare Fig. 5). 

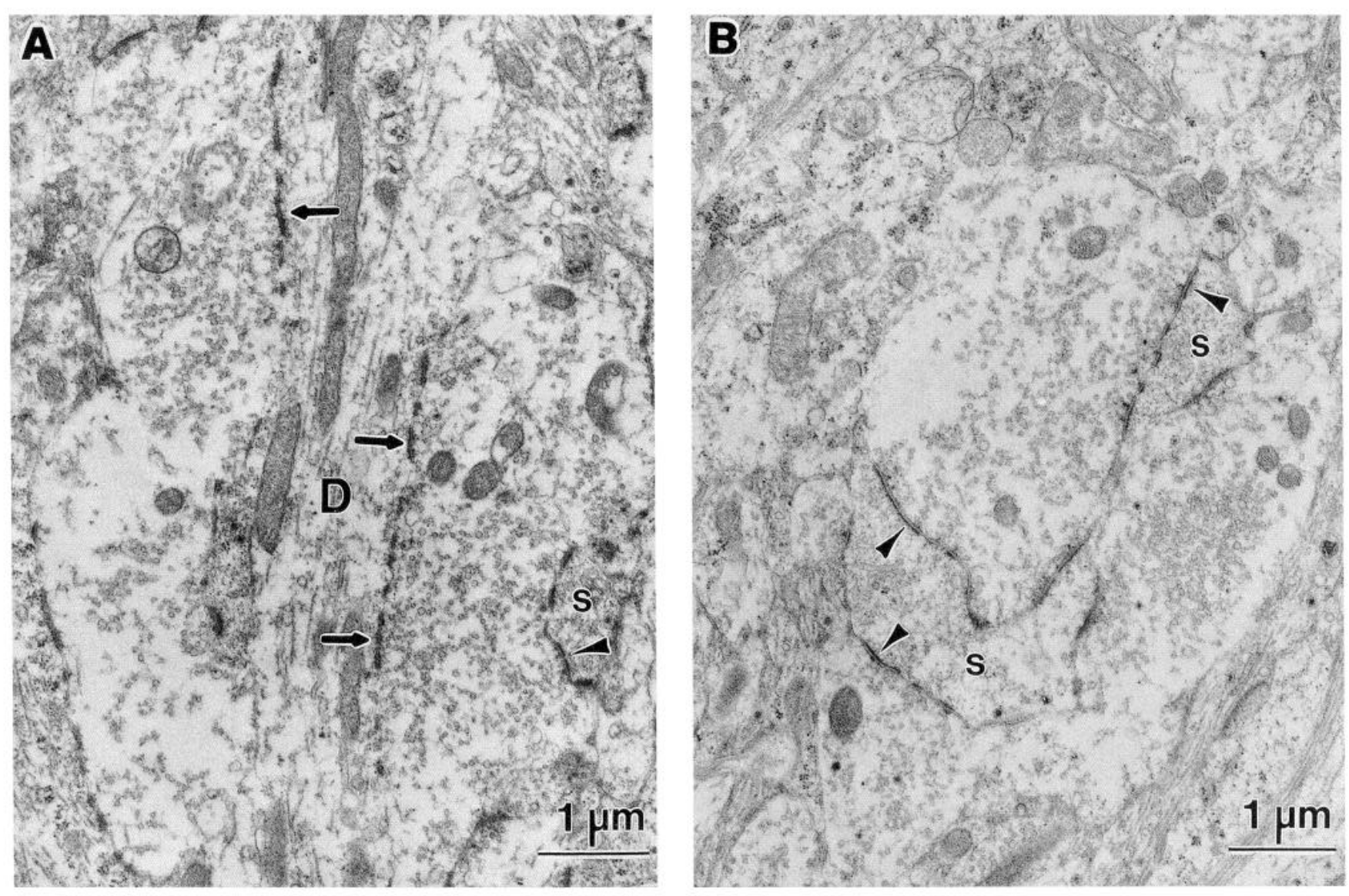

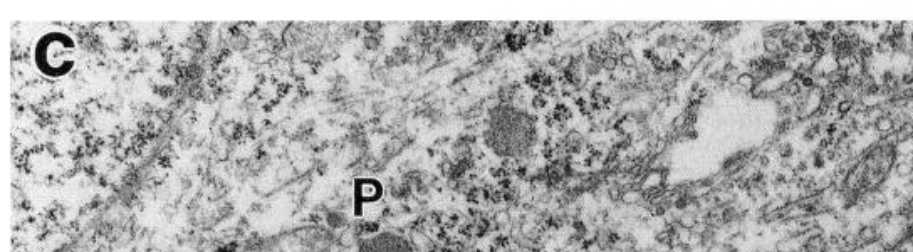

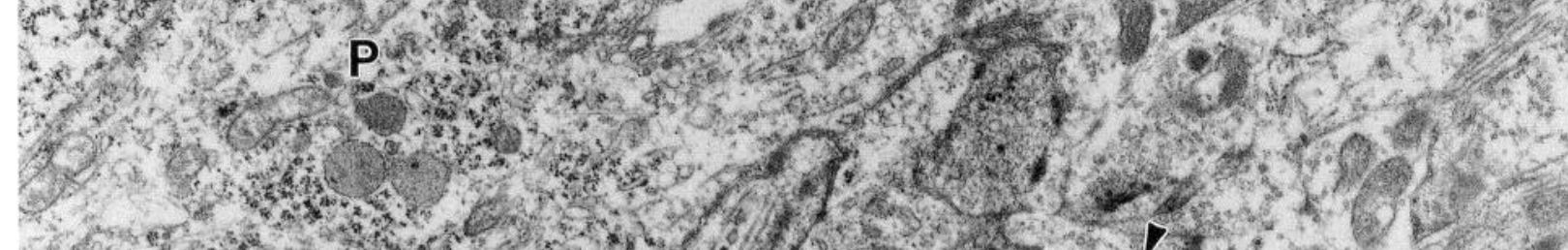

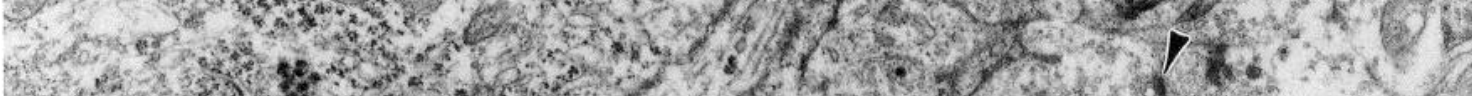

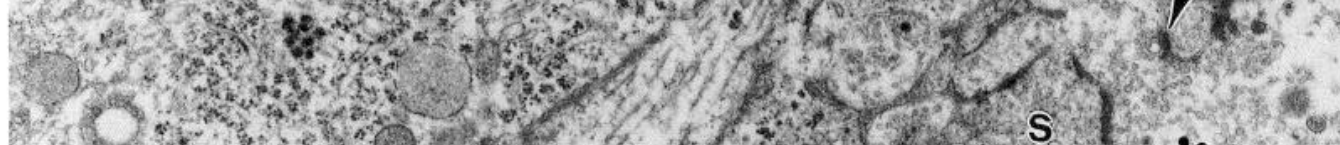

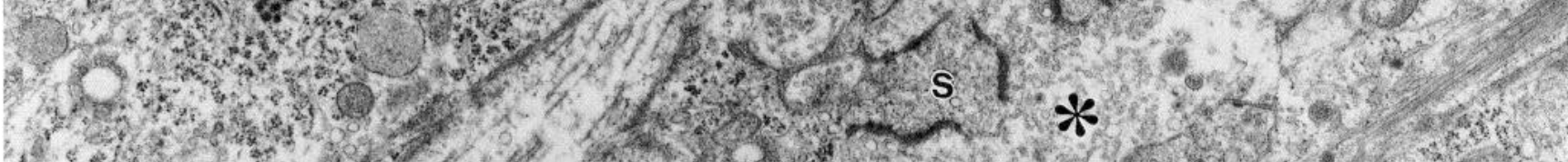

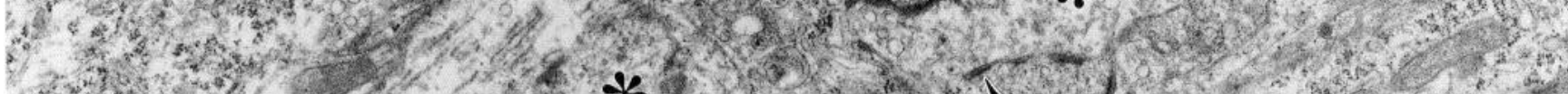

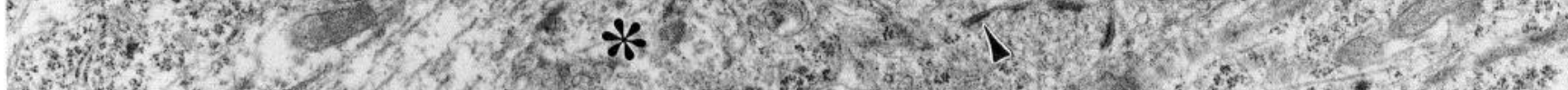

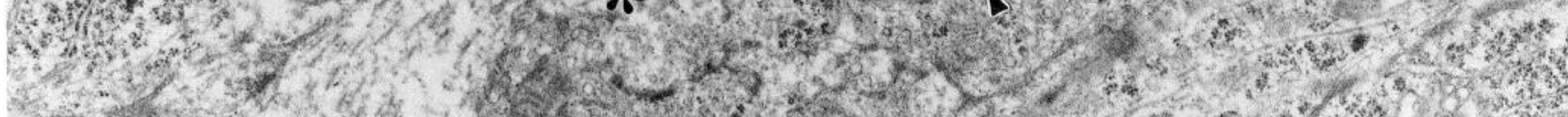

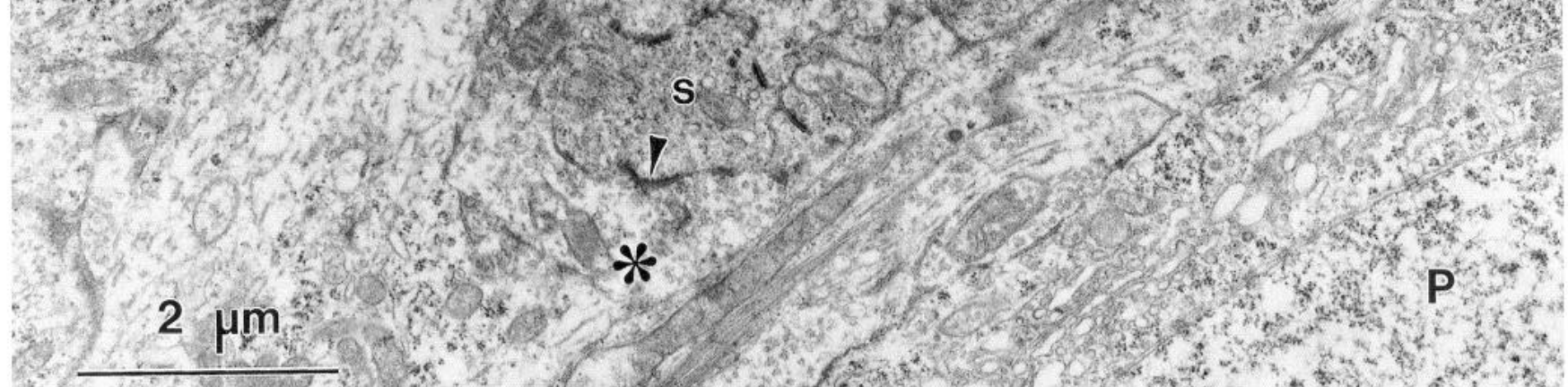



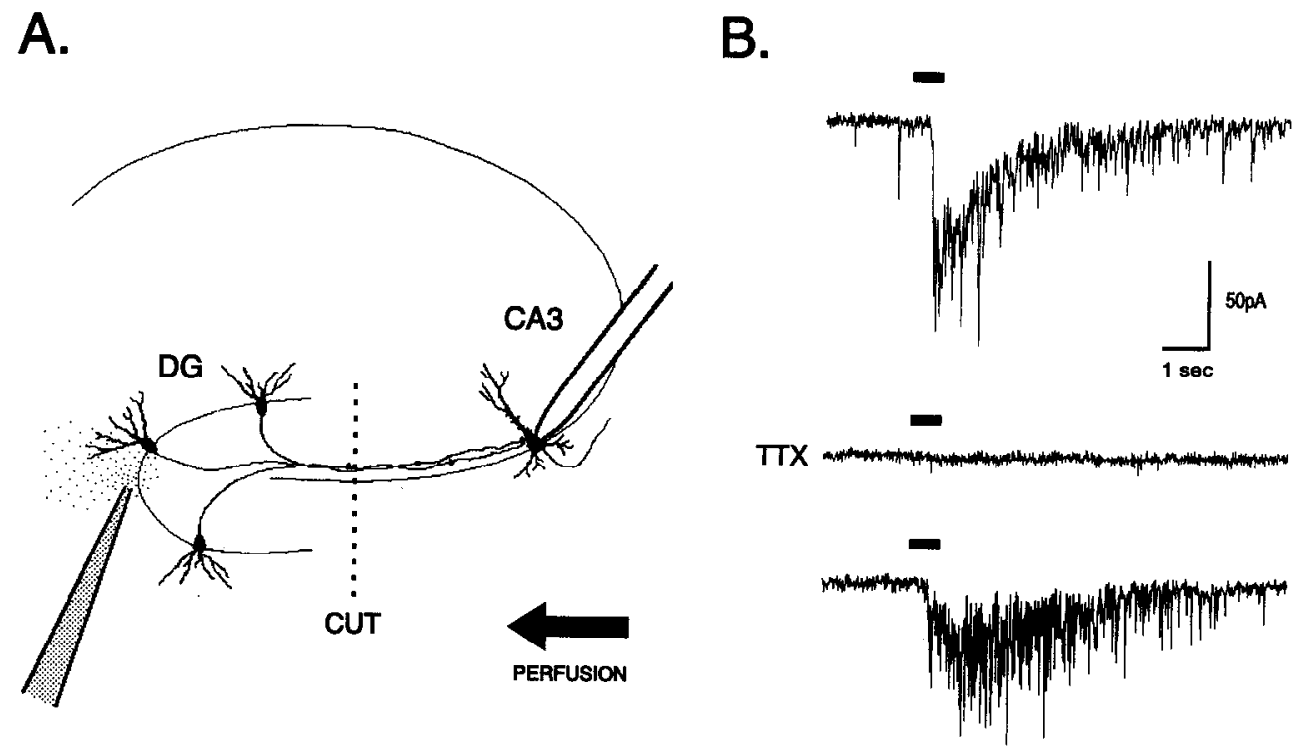

Figure 11. Excitatory MF connections were reestablished in cultured slices within 2 weeks after lesioning of the MF pathway. Brief application of glutamate to the DG elicited responses in CA3 pyramidal neurons on the distal side of the lesion. $A$, Schematic representation of the experimental setup. Tip of a puffer pipette containing $10 \mathrm{~mm}$ glutamate was placed in the slice next to the dentate granule cell layer. Responses were recorded in CA3 pyramidal cells distal to the lesion using the whole-cell voltage-clamp configuration. We examined only slices in which the lesion site was clearly evident. A bath perfusion of oxygenated saline was maintained at $1-2 \mathrm{ml} / \mathrm{min}$ in the direction of the arrow. $B$, Excitatory postsynaptic currents (EPSCs) recorded in a single CA3 pyramidal neuron (holding potential $=-70 \mathrm{mV}$ ) in response to brief $(500 \mathrm{msec}$ ) glutamate application (bar) to granule cells. The response was entirely abolished by $1 \mu \mathrm{M}$ TTX in the bath (second trace), indicating that the response was not due to diffusion of glutamate to area CA3. Recovery of the excitatory response (third trace) following washout of TTX was seen after 0.5-2 hr. The recording pipette contained QX-314 to abolish sodium spikes in the recorded cells. The EPSCs recorded from pyramidal neurons likely represent a combination of both MF and recurrent pyramidal cell inputs since collaterals of CA3 pyramidal cells in slice culture are known to form excitatory synaptic contacts with neighboring pyramidal cells (Frotscher and Gähwiler, 1988).

reversibly abolished when TTX $(1 \mu \mathrm{M})$ was added to the bath $(n=3)$. These results provide strong evidence that an excitatory synaptic input from dentate to $\mathrm{CA} 3$ was established de novo after a lesion, and it is likely that this was mediated by growth of MFs and formation of new synaptic connections with pyramidal neurons.

\section{Mossy fiber growth in nonlesioned slices: time-lapse confocal imaging}

The MF growth and synapse formation observed in cultured slices may have been induced by the lesion: such growth conceivably might not occur in "normal," nonlesioned cultures. We used time-lapse confocal imaging to determine directly if newly developing, nonsevered MFs continue to grow in isolated living brain slices. We examined fiber growth in live, 400- $\mu \mathrm{m}$-thick hippocampal slices in which the MF tract was left intact (i.e., nonlesioned). Since many MFs are extending and forming synaptic contacts during the first postnatal week in vivo (Amaral and Dent, 1981), we examined slices derived from P4-P6 rats.

To vitally stain the MFs, a fluorescent membrane dye, DiI or $\mathrm{DiO}$, was injected into the dentate hilus adjacent to the granule cell layer, as described above (see Fig. 6). After a variable incubation period (4-48 hr), the living slices were mounted in a closed chamber and placed on the heated stage of a confocal microscope. Low-magnification images always revealed an intensely fluorescent bolus in the hilar region where the dye was injected. In approximately one-half of the slices there was also a bundle of labeled fibers that projected into area CA3, and this bundle invariably occupied the SL, where the MFs normally course. The tips of labeled fibers in the bundle were observed up to $1 \mathrm{~mm}$ away from the injection site within just a few hours after injection, indicating that the dyes diffused rapidly within the living neurons. The number of labeled fibers, as well as the distance that the fibers extended into CA3, was variable from slice to slice. As a general rule, labeled fibers in slices from younger animals (P4) did not extend as far into CA3 as fibers in older slices $(\geq \mathrm{P} 6)$. These observations are consistent with the idea that the labeled fibers correspond to the MFs, and that they are rapidly extending at this stage of development.

High-magnification confocal images of acutely isolated and labeled slices showed that fibers within the SL had small growth cones $(5-10 \mu \mathrm{m}$ in length) with short $(<5 \mu \mathrm{m})$ filopodia and small lamellae. Most fibers in the SL were unbranched, although fine filopodia were seen to emanate from the sides of many of the fibers. Collection of single confocal images at 1-5 min intervals, or stacks of images at 5-10 min intervals (see Materials and Methods), showed that individual labeled fibers within the SL were highly dynamic and were elongating at rates of 5-35 $\mu \mathrm{m} / \mathrm{hr}$ (Fig. 12). Sometimes the leading growth cone made a transition from a motile to a quiescent phase (Fig. 13), which may possibly coincide with synaptogenic interactions between the growth cone and target cells. We also observed foci of filopodial activity along the length of some fibers (Fig. 14), suggesting that dynamic interactions with neighboring cells persist at discrete sites along the axon even as the axons continue elongating. Together, these results demonstrate that intact MFs in isolated hippocampal slices continue to extend along their normal pathway for at least $48 \mathrm{hr}$ after removal from the brain.

\section{Discussion}

Our goal was to assess the development of MFs in excised hippocampal slices in vitro. We have confirmed that MFs continue 

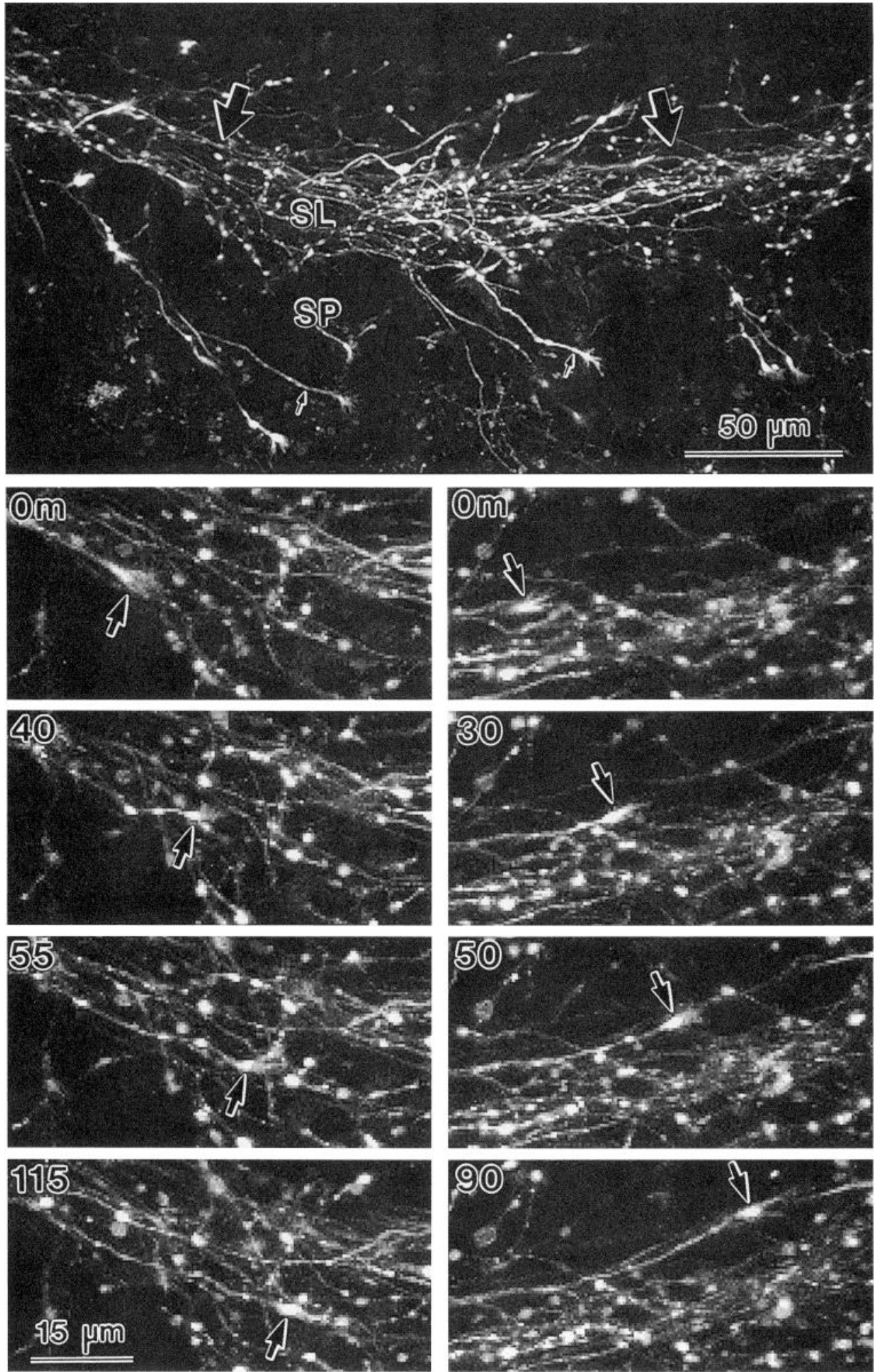

Figure 12. Confocal time-lapse imaging of DiI-labeled MFs in area CA3 of a living hippocampal slice from a P6 rat $(\mathrm{P} 6,8 \mathrm{hr}$ in vitro). Top panel is a low-magnification image of area $\mathrm{CA} 3$ showing many labeled fibers in the SL (large arrows), where MFs normally course. A few fibers (small arrows) also extend into the pyramidal cell layer $(S P)$. The two columns below show selected images from two time-lapse sequences of different regions of the SL (locations indicated by the large arrows in the field above). Note in each time-lapse sequence the extension of labeled fibers, tipped by small growth cones (arrows), within the $S L$. Time is shown in minutes. Each image in this figure is a z-axis composite of five individual confocal images taken at $2 \mu \mathrm{m}$ intervals; thus, the apparent depth of field is about 10 $\mu \mathrm{m}$. to grow along their normal suprapyramidal pathway and form appropriate synaptic connections de novo with CA3 pyramidal cells. The new MF synaptic connections were examined with regard to general distribution within hippocampal subfields, cellular specificity, morphological development of synaptic specializations, and functionality. It was determined that MF synapses that were formed entirely in vitro are normal by a wide range of criteria, although they are dispersed more widely than normal along the target cell apical dendrite.

\section{Use of synapsin I antiserum to visualize mossy fiber synaptic terminals}

To facilitate evaluation of MF terminal distribution, we used an antiserum against Syn-I (DeCamilli et al., 1983a; for review, 
Figure 13. Time-lapse confocal imaging of DiO-labeled MFs in a live hippocampal slice (P5). Upper panel shows labeled fibers $30 \mu \mathrm{m}$ below the surface of the slice in area CA3, nearly $1 \mathrm{~mm}$ away from the site of dye injection in the dentate. Several labeled fibers tipped by growth cones (arrows) are evident. The majority of labeled fibers are located within a $50-\mu \mathrm{m}$-wide strip (SL) and are oriented away from the dentate (beyond upper left of field). Lower panel shows selected images from a time-lapse sequence (spanning $2.5 \mathrm{hr}$ ) of boxed region in upper panel. This growth cone (large arrows) translocated forward at about $12 \mu \mathrm{m} / \mathrm{hr}(0-60 \mathrm{~min})$, exhibited profuse filopodial activity (small arrows at $60 \mathrm{~min}$ ), and then abruptly halted (90 min). Fine filopodial appendages (small arrows at $150 \mathrm{~min}$ ) then rapidly emerged, and the growth cone maintained this configuration for several hours. Other growth cones continued to grow through this area, suggesting that the slice was still healthy.

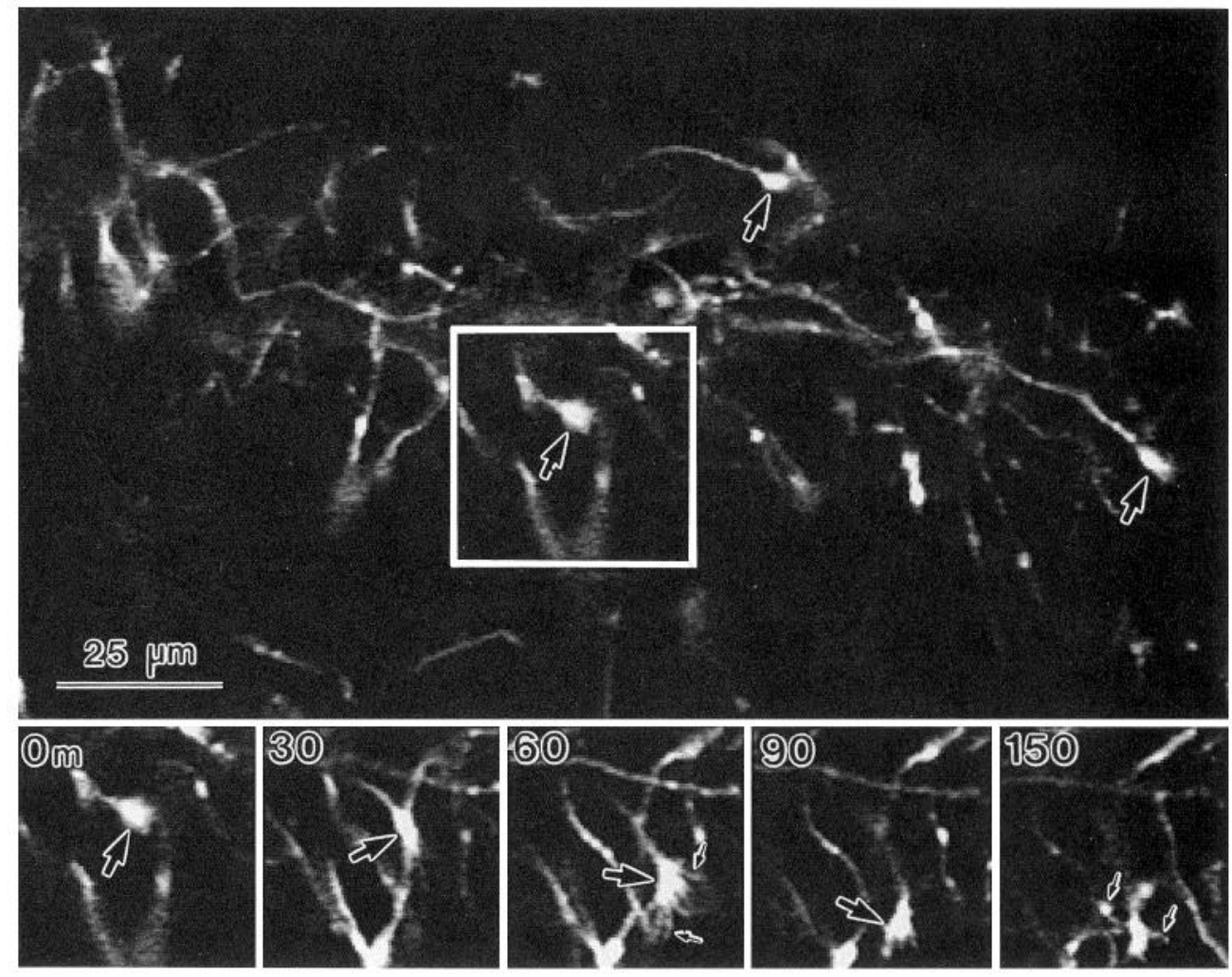

see DeCamilli et al., 1990), a protein specifically associated with small clear synaptic vesicles (DeCamilli et al., 1983a,b; Navone et al., 1984). Previous immunofluorescence staining of tissue sections with the Syn-I antiserum gave a punctate pattern of staining that was consistent with its marking synaptic boutons, including the giant boutons of the hippocampal MFs (DeCamilli et al., 1983a). More recent work has shown that the development of Syn-I immunoreactivity within mammalian brain is highly correlated with the formation of synaptic boutons as seen in the electron microscope (Mason, 1986; Chun and Shatz, 1988; Moore and Bernstein, 1989). On a cellular level, Syn-I-immunoreactive puncta in cultured hippocampal neurons were shown to correspond to focal accumulations of vesicles at ultrastructurally identifiable synapses (Fletcher et al., 1991). While growth cones and other nonsynaptic sites along developing axons may also be immunoreactive (Mason, 1986; Fletcher et al., 1991), staining in these regions is granular and is not comparable to the intense, focal immunoreactivity normally seen at sites of synaptic contact (Fletcher et al., 1991). Thus, focal sites of intense immunoreactivity appear to correspond to presynaptic boutons.

In our hands, en bloc immunostaining of acutely isolated hippocampal tissue with Syn-I antiserum gave a pattern of immunoreactivity that was comparable to that seen previously using semithin sections of perfusion-fixed rat brains (DeCamilli et al., 1983a). Although small immunoreactive puncta were found in all regions of the hippocampus, the distribution of large puncta was highly restricted. The large puncta coincided precisely with the known distribution of giant MF terminals in the dentate hilus and SL of CA3. The identity of the large puncta as MF giant terminals was further confirmed using the dentateless cultures: no large Syn-I puncta were observed when MFs were excluded from the cultures.

The progressive accumulation of Syn-I immunoreactivity we observed within the SL during the first postnatal week is comparable to that seen by others (Zimmer and Haug, 1978; Amaral and Dent, 1981) using the Timm's sulfide silver stain, which detects MF terminals based on their relatively high content of zinc (Haug, 1967). At midseptotemporal levels there is little concentration of Timm's staining in the SL on P1, whereas by P3 the SL is more sharply defined and there are individual particles, indicative of MF boutons. The number and size of the Timm's-stained particles increase over the next 2 postnatal weeks, as we observed with Syn-I staining.

The Syn-I accumulation we observed in the SL is also consistent with other indicators of in vivo MF development and synaptogenesis. Ultrastructural observations of developing tissue revealed that many immature MF-pyramidal cell contacts are being formed during the first postnatal week (Stirling and Bliss, 1978; Amaral and Dent, 1981). Furthermore, MF-evoked synaptic potentials in area CA3 are first observed between P2 and P5 in the rat (Bliss et al., 1974). Thus, the emergence of Syn-I immunoreactivity within the SL during the first postnatal week coincides precisely with the period when MFs are contacting and forming functional synaptic connections with pyramidal cells.

\section{Mossy fiber synapses in normal organotypic slice cultures}

The distribution of large Syn-I puncta in normal organotypic cultures is very similar to the pattern of Timm's staining observed by others (Gähwiler, 1984b; Zimmer and Gähwiler, 1984). Timm's-stained terminals are consistently found in the hilus and in the SL of area CA3, and occasionally within the SP. Neither giant Syn-I puncta (this study) nor Timm's-stained terminals (Zimmer and Gähwiler, 1987) are found when slices are cultured without the DG, which is the source of the MFs. Furthermore, there is a striking similarity in distribution of large 

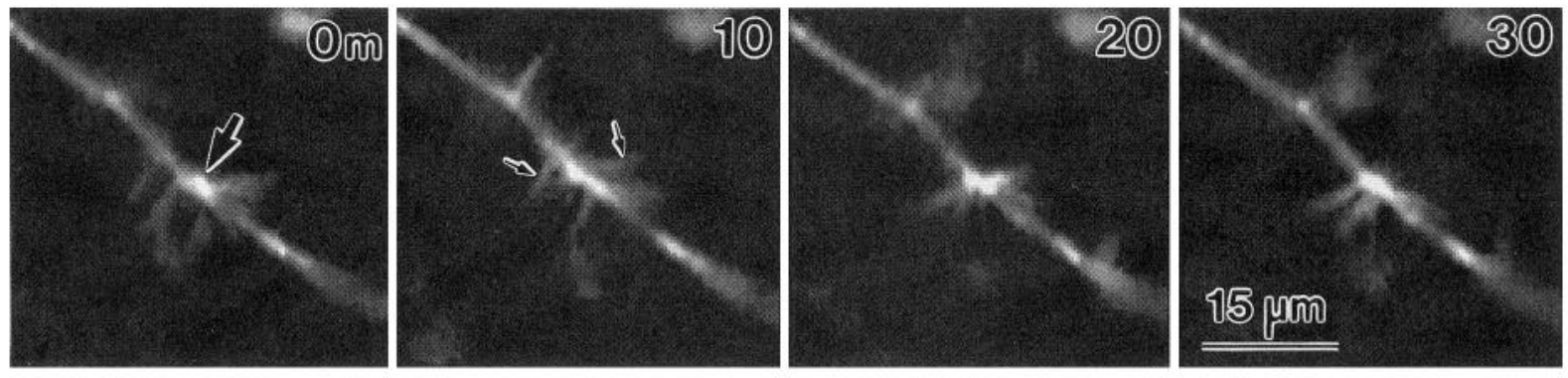

Figure 14. Time-lapse sequence showing focal protrusive activity at a small varicosity (large arrow) along a DiO-labeled MF axon in area CA3. Dynamic, filopodia-like structures (small arrows) were observed at this location for more than $1.5 \mathrm{hr}$. These varicose regions may indicate nascent, en passant synaptic sites. Time is shown in minutes. The slice was prepared acutely from a P4 rat.

puncta and Timm's-positive varicosities when slices are cultured after a lesion of the MF tract (see below). Thus, in hippocampal tissue there is good correlation between the distribution and appearance of the Timm's-stained terminals and the large Syn-I puncta, both in vivo and in tissue cultured under various conditions. Taken together, this is strong evidence that the Timm's-stained terminals and the large Syn-I puncta correspond to the same structures, and that these structures are MF giant terminals.

Ultrastructurally, the giant synaptic terminals we observed in normal slice cultures resemble those seen by others (Zimmer and Gähwiler, 1984; Frotscher and Gähwiler, 1988). One difference from terminals in vivo is that spines invaginated or perforated giant terminals less frequently in cultured slices. Although we have only examined slices cultured for up to $14 \mathrm{~d}$, other published micrographs of older ( $>20$ days in vitro) cultures only rarely reveal perforated terminals (Zimmer and Gähwiler, 1984; Frotscher and Gähwiler, 1988). Since MF terminals from age-matched (P21) tissue in situ are normally invaginated by an average of over two dendritic spine elements (Amaral and Dent, 1981), the postsynaptic specializations (thorny excrescences) may be less complex in slice cultures than in intact brain. Moreover, the giant terminals in cultured slices generally have a looser packing of clear synaptic vesicles than found in tissue from perfusion-fixed adult rats (cf. Blackstad and Kjaerheim, 1961; Amaral and Dent, 1981). Consequently, terminals in slice culture more closely resemble those seen in 9-11-d-old rats, where the terminals are less convoluted, have a looser packing of vesicles, and are only rarely perforated by dendritic spines (Amaral and Dent, 1981). Development of synaptic specializations may thus proceed at a slower rate in culture. Alternatively, full maturation may depend upon normal synaptic input to the granule cells (Frotscher et al., 1977), physiological patterns of activity, or some other afferent pathways or factors not present in the slice cultures.

\section{Formation of new mossy fiber synaptic terminals}

Our goal was to determine whether synaptic contacts are formed de novo by MFs in culture, but in normal organotypic slices we could not differentiate newly formed synapses from extant synapses. Thus, we effectively removed extant MF synapses by lesioning the MFs. We showed with Syn-I staining that the old (extant) MF terminals are not preserved when the dentate granule cells are completely removed before culturing (see Fig. 4). However, when the granule cells are retained in slices cultured after lesioning, new MF terminals are detected by Syn-I staining as well as by electron microscopy. The evidence indicates that the new giant terminals emerged in CA3 as a consequence of MF growth and de novo synaptogenesis. Since dentate granule cells are still undergoing massive proliferation at P7 (Schlessinger et al., 1975) when the slices are harvested, the MF synapses that were formed de novo in culture may have arisen from either newly developing or regenerating MFs.

Our results with Syn-I staining of MF-lesioned cultures are essentially the same as those of Zimmer and Gähwiler (1987) using the Timm's method. MF-like terminals were found on the distal side of the lesion after 2 weeks in culture, indicating that MFs grow and form synapses de novo. In addition, the MF terminal zone on both the proximal (dentate) and distal (CA1) sides of the lesion was seen to expand into the pyramidal layer in both Syn-I- (present results) and Timm-stained (Zimmer and Gähwiler, 1987) material. The expansion of the MF terminal zone that is observed in cultured slices after a lesion may be analogous to the redistribution of MFs that occurs after an intracerebral lesion in developing rats. In the rat, lesions in CA3 cause MFs to grow abnormally into adjacent regions, forming aberrant intra- and infrapyramidal terminals (Laurberg and Zimmer, 1980). It has been suggested that the expansion of MF terminal zones seen both in vivo and in vitro is due to a limited number of suprapyramidal postsynaptic sites relative to the number of innervating fibers, forcing some fibers into intra- and infrapyramidal regions (Gaarskjaer, 1978; Laurberg and Zimmer, 1980; Zimmer and Gähwiler, 1984, 1987). An alternative explanation for the spread of MF terminals after a lesion in vitro is that MFs can invade the SP when they lose their normal guidance cues within the SL. Indeed, DiI labeling of MFs after lesioning showed that fibers commonly radiate into the SP from the cut stump when the laminae are not aligned and the normal MF pathway is disrupted. Nevertheless, once fibers relocate the SL, they frequently course in an undeviated manner along this pathway. The SL may contain a more favorable environment for MF growth, and MF affinity for the SL may foster growth along this pathway. This may produce a greater concentration of giant terminals in the suprapyramidal zone, especially in more distal CA3 regions, as we and others (Zimmer and Gähwiler, 1987) have observed.

DiI labeling of lesioned cultures revealed that fibers that grow across the lesion form axonal expansions that are morphologically similar to MF expansions found in vivo and in normal organotypic cultures. The large en passant expansions along MFs in vivo (Claiborne et al., 1986) correspond to the giant synaptic boutons and indicate sites of synaptic contact with pyramidal cells (Blackstad and Kjaerheim, 1961). These irregularly shaped expansions are typically $2-10 \mu \mathrm{m}$ in diameter, and they are 
either intimately associated with the axon cylinder or attached via a short stalk. Several filamentous extensions $(1-30 \mu \mathrm{m}$ in length) emanate from the mature MF expansions in area CA3 (Claiborne et al., 1986) as well as in the dentate hilus (Amaral, 1979). These "filiform extensions" have also been seen to emanate from giant expansions along HRP-filled MFs in normal organotypic slice cultures (Zimmer and Gähwiler, 1984). We found that comparable expansions with filiform cxtensions werc formed de novo by fibers that grew across the lesion from dentate to CA3. These specialized en passant structures were elaborated in both the SL and SP of area CA3, which coincides with the distribution of large Syn-I puncta in these cultures. Thus, it is very likely that the large complex varicosities we observed with DiI staining correspond to giant synaptic terminals of the MFs.

Ultrastructurally, the new MF terminals that formed de novo after a lesion were very similar to those found in the normal cultures, having reached a comparable size and morphological complexity. The normal distribution of symmetrical and asymmetrical junctions was maintained in terminals formed in vitro, and spines were not seen to perforate the giant terminals. These morphological characteristics were observed irrespective of the location of the synapse, whether in the SL or SP. We saw very few MF-like terminals associated with pyramidal somata in the SP. Although Amaral and Dent (1981) have observed that some MFs in vivo run perpendicularly within the SP and make symmetrical contacts with both the proximal dendrites and somata of pyramidal cells, the prevalence of such axosomatic contacts is unclear. We did see many DiI-labeled fibers coursing in such a manner in the lesioned slices, but our electron microscopy data did not reveal MF-like terminals synapsing directly upon pyramidal cell somata.

\section{Functional reinnervation in slice cultures after a lesion}

CA3 pyramidal neurons in normal slice cultures respond to electrical field stimulation of the DG (Gähwiler, 1981, 1988; Dani et al., 1992), suggesting that the MF-pyramidal cell connections are intact in these cultures. Nevertheless, it was not previously determined if MFs form de novo functional synaptic connections with CA3 pyramidal cells in culture. In MF-lesioned slices cultured for $\geq 10 \mathrm{~d}$, we found that direct electrical stimulation of the DG elicited responses in pyramidal neurons across the lesion. Since pyramidal cell axons sometimes invade the DG (M. E. Dailey, unpublished observations; also Zimmer and Gähwiler, 1984), these axons could conceivably mediate direct nonsynaptic, antidromic excitation of CA3 pyramidal cells. However, local application of glutamate to the DG also produced robust excitatory responses in CA3 pyramidal neurons. Although glutamate is excitatory for CA3 pyramidal cells as well as for dentate granule cells, it is unlikely that the inward currents we observed resulted from glutamate diffusion to CA3 since (1) a rapid perfusion was flowing in the opposite direction; (2) responses were observed when the recording pipette contained $1 \mathrm{mM}$ QX-314 (an intracellular $\mathrm{Na}^{+}$channel blocker) to prevent direct firing of the target cell, but were reversibly abolished by $1 \mu \mathrm{M}$ TTX in the bath; and (3) no glutamate-induced responses were seen when the pipette was raised just above the dentate. Thus, excitation of CA3 pyramidal neurons was dependent upon stimulation of pathways between the dentate and CA3, but was independent of firing of target CA3 neurons. We conclude that excitation of pyramidal cells across the lesion was mediated by MF synaptic input that must have developed in vitro.

\section{Comparison with other in vitro systems}

Functional reinnervation in vitro has been observed between cocultured tissues from a variety of CNS regions (e.g., Gähwiler and Brown, 1985; Yamamoto et al., 1989; Bolz et al., 1992). Gähwiler and colleagues have shown that cholinergic fibers from cultured septal explants can invade normal target regions and form functional synaptic connections within cocultured hippocampal tissue (Gähwiler and Hefti, 1984; Gähwiler and Brown, 1985). Likewise, coculture studies using thalamus and visual cortex have shown that thalamic fibers extend into, branch in, and terminate within the correct cortical layer irrespective of the pathway taken by the fibers (Yamamoto et al., 1989, 1992; Bolz et al., 1990, 1992; Molnár and Blakemore, 1991). The present results indicate that the hippocampal MFs in slice culture, like fibers in cultured visual cortex, are capable of forming functional synaptic connections with appropriate target cells even when the normal axonal trajectories are not followed precisely. However, it would appear that for the hippocampal MF system the distribution of synaptic sites on target cells is altered (expanded) slightly when the normal MF course is disrupted. This alteration could be detected in the present study because we were able to take advantage of the large size of the MF terminals and thereby localize the synapses directly using the Syn-I staining and the electron microscope. The in vivo restriction of MFs to the SL may normally serve to confine MF synaptic input to a narrow strip along the apical dendrites of pyramidal cells. Whether or not the expansion of MF synaptic input along the main apical dendritic shaft has important physiological consequences will require further work.

An important difference from other in vitro systems studied is that the MF origins and targets are entirely contained within single isolated slices. Consequently, it is not necessary for developing fibers to traverse unusual culture terrain or contact abnormal intermediate targets before innervating normal, relatively intact target regions. Furthermore, in nonlesioned slices the normal anatomical arrangement of afferent fibers and target cells is maintained. This affords direct examination of developmental events within a complex tissue environment similar to that found in situ.

\section{Dynamics of mossy fiber growth}

Recent advances in confocal microscopy (for review, see Fine et al., 1988; Pawley, 1990) and vital fluorescence staining of neural tissue with membrane dyes (Honig and Hume, 1986) now permit direct observation of cellular dynamics within live tissue slices of developing mammalian CNS (Smith et al., 1990; O'Rourke et al., 1992). Several studies have examined axon growth and growth cone dynamics in target regions of intact or semi-intact nonmammalian vertebrate brain (Harris et al., 1987; O'Rourke and Fraser, 1990; Kaethner and Stuermer, 1992). However, axonal dynamics in target regions of mammalian CNS have not been studied extensively. Here we provide the first direct examination of growth of identified CNS axons in normal target regions using excised slices of live mammalian brain tissue

Using time-lapse confocal imaging, we directly demonstrated that MF growth persists in normal isolated slices. Even after many hours in vitro, labeled fibers were growing within the SL, suggesting that guidance cues for MFs are retained in the isolated slices. We were not able to determine conclusively whether any of the growing MFs in nonlesioned slices formed synaptic con- 
nections de novo. However, since giant synapses in normal cultures are still largely confined to the SL after 2 weeks in vitro, it may be expected that any new synaptic contacts formed by growing MFs in these cultures will be restricted to the normal target layer (i.e., the SL).

Each MF normally forms several en passant synaptic contacts with pyramidal cells but does not branch significantly in target regions. It is not presently known if MFs establish the initial nascent synaptic contacts at the growing tip, or if synaptic contacts are later initiated back along the axon. We observed dynamic protrusive activity at sites along developing axons, and this activity may indicate continuing interaction with target cells. Such activity could mark sites of nascent synaptic contact, and the protrusive activity may serve to establish additional synaptic contacts. An intriguing possibility is that the active filopodial structures are precursors to the extensions that emanate from mature MF varicosities and are known to form synaptic contacts (Amaral, 1979). We also observed that growth cones at the tips of fibers sometimes rapidly ceasc motilc activity and remain quiescent for extended periods of time. Further work will be necessary to characterize such events more fully, and to determine if they are correlates of synapse formation.

The present work establishes the means by which to visualize directly the dynamic cellular activities of target cell selection and synapse formation in developing mammalian CNS tissue. The emerging ability to visualize simultaneously afferent axons and target cells should reveal the nature of the interaction of synapse forming partners and should help determine whether target cells are passive recipients or active players in CNS synaptogenesis. Direct viewing of axon-target cell interactions in live developing tissues will undoubtedly advance our understanding of the important but poorly understood process of synaptogenesis in the CNS.

\section{References}

Amaral DG (1979) Synaptic extensions from the mossy fibers of the fascia dentata. Anat Embryol (Berl) 155:241-251.

Amaral DG, Dent JA (1981) Development of the mossy fibers of the dentate gyrus: I. A light and electron microscopic study of the mossy fibers and their expansions. J Comp Neurol 195:51-86.

Amaral DG, Witter MP (1989) The three-dimensional organization of the hippocampal formation: a review of anatomical data. Neuroscience 31:571-591.

Blackstad TW, Kjaerheim $\AA$ (1961) Special axo-dendritic synapses in the hippocampal cortex: electron and light microscopic studies on the layer of mossy fibers. J Comp Neurol 117:133-157.

Blanton MG, Lo Turco JJ, Kriegstein AR (1989) Whole cell recording from neurons in slices of reptilian and mammalian cerebral cortex. J Neurosci Methods 30:203-210.

Bliss TVP, Chung SH, Stirling RV (1974) Structural and functional development of the mossy fibre system in the hippocampus of the post-natal rat. J Physiol (Lond) 239:92P-94P.

Bolz J, Novak N, Gotz M, Bonhoeffer T (1990) Formation of targetspecific neuronal projections in organotypic slice cultures from rat visual cortex. Nature 346:359-362.

Bolz J, Novak N, Staiger V (1992) Formation of specific afferent connections in organotypic slice cultures from rat visual cortex cocultured with lateral geniculate nucleus. J Neurosci 12:3054-3070.

Chun JM, Shatz CJ (1988) Distribution of synaptic vesicle antigens is correlated with the disappearance of a transient synaptic zone in the developing cerebral cortex. Neuron 1:297-310.

Claiborne BJ, $\Lambda$ maral DG, Cowan WM (1986) $\Lambda$ light and electron microscopic analysis of the mossy fibers of the rat dentate gyrus. $J$ Comp Neurol 246:435-458.

Cooper MW, Smith SJ (1992) A real-time analysis of growth conetarget cell interactions during the formation of stable contacts between hippocampal neurons in culture. J Neurobiol 23:814-828.
Cowan WM, Stanfield BB, Amaral DG (1981) Further observations on the development of dentate gyrus. In: Studies in developmental neurobiology (Cowan WM, ed), pp 395-435. London: Oxford UP.

Dailey ME, Smith SJ (1991) Development of mossy fiber axons and synapses in rat hippocampal slices examined with a scanning laser confocal microscope. Soc Neurosci Abstr 17:532.

Dani JW, Chernjavski A, Smith SJ (1992) Neuronal activity triggers Ca waves in hippocampal astrocyte networks. Neuron 8:429-440.

DeCamilli P, Camcron R, Grecngard P (1983a) Synapsin I (protcin I), a nerve terminal-specific phosphoprotein: I. Its general distribution in synapses of the central and peripheral nervous system demonstrated by immunofluorescence in frozen and plastic sections. J Cell Biol 96:1337-1354

DeCamilli P, Harris SM, Huttner WB, Greengard P (1983b) Synapsin I (protein I), a nerve terminal-specific phosphoprotein: II. Its specific association with synaptic vesicles demonstrated by immunocytochemistry in agarose-embedded synaptosomes. J Cell Biol 96:13551373.

DeCamilli P, Benfenati F, Valtorta F, Greengard P (1990) The synapsins. Annu Rev Cell Biol 6:433-460.

Fine A, Amos WB, Durbin RM, McNaughton PA (1988) Confocal microscopy: applications in neurobiology. Trends Neurosci 11:346351.

Fletcher TL, Cameron P, DeCamilli P, Banker G (1991) The distribution of synapsin I and synaptophysin in hippocampal neurons developing in culture. J Neurosci 11:1617-1626.

Frotscher M, Gähwiler BH (1988) Synaptic organization of intracellularly stained CA3 pyramidal neurons in slice cultures of rat hippocampus. Neuroscience 24:541-551.

Frotscher M, Hámori J, Wenzel J (1977) Transneuronal effects of entorhinal lesions in the early postnatal period on synaptogenesis in the hippocampus of the rat. Exp Brain Res 30:549-560.

Gaarskjaer FB (1978) Organization of the mossy fiber system of the rat studied in extended hippocampi. I. Terminal area related to number of granule and pyramidal cells. J Comp Neurol 178:49-72.

Gähwiler BH (1981) Organotypic monolayer cultures of nervous tissue. J Neurosci Mcthods 4:329-342.

Gähwiler BH (1984a) Development of the hippocampus in vitro: cell types, synapses, and receptors. Neuroscience 11:751-760.

Gähwiler BH (1984b) Slice cultures of cerebellar, hippocampal and hypothalamic tissue. Experientia 40:235-243.

Gähwiler BH (1988) Organotypic cultures of neural tissue. Trends Neurosci 11:484-489.

Gähwiler BH, Hefti F (1984) Guidance of acetylcholinesterase-containing fibres by target tissue in co-cultured brain slices. Neuroscience 13:681-689.

Gähwiler BH, Brown DA (1985) Functional innervation of cultured hippocampal neurons by cholinergic afferents from co-cultured septal explants. Nature 313:577-579.

Hamill OP, Marty A, Neher E, Sakmann B, Sigworth FJ (1981) Improved patch-clamp techniques for high resolution current rccording from cells and cell-free membrane patches. Pfluegers Arch 39:85-101.

Hamlyn LH (1962) The fine structure of the mossy fibre endings in the hippocampus of the rabbit. J Anat 96:112-120.

Harris WA, Holt CE, Bonhoeffer F (1987) Retinal axons with and without their somata, growing to and arborizing in the tectum of Xenopus embryos: a time-lapse video study of single fibres in vivo. Development 101:123-133.

Haug, F-MS (1967) Flectron microscopical localization of the zinc in hippocampal mossy fibre synapses by a modified sulfide silver procedure. Histochemie 8:355-368.

Honig MG, Hume RI (1986) Fluorescent carbocyanine dyes allow living neurons of identified origin to be studied in long-term cultures. J Cell Biol 103:171-187.

Kaethner RJ, Stuermer CAO (1992) Dynamics of terminal arbor formation and target approach of retinotectal axons in living zebrafish embryos: a time-lapse study of single axons. J Neurosci 12:32573271 .

Laurberg S, Zimmer J (1980) Lesion-induced rerouting of hippocampal mossy fibers in developing but not in adult rats. J Comp Neurol 190:627-650.

Mason CA (1986) Axon development in mouse cerebellum: embryonic axon forms and expression of synapsin I. Neuroscicnce 19:13191333.

McConnell SK, Ghosh A, Shatz CJ (1989) Subplate neurons pioneer 
the first axon pathway from the cerebral cortex. Science $245: 978-$ 982.

Molnár Z, Blakemore C (1991) Lack of regional specificity for connections formed between thalamus and cortex in coculture. Nature 351:475-477.

Moore RY, Bernstein ME (1989) Synaptogenesis in the rat suprachiasmatic nucleus demonstrated by electron microscopy and synapsin I immunoreactivity. J Neurosci 9:2151-2162.

Navone F, Greengard P, DeCamilli P (1984) Synapsin I in nerve terminals: selective association with small synaptic vesicles. Science 226:1209-1211.

O'Rourke NA, Fraser SE (1990) Dynamic changes in optic fiber terminal arbors lead to retinotopic map formation: an in vivo confocal microscopic study. Neuron 5:159-171.

O'Rourke NA, Dailey ME, Smith SJ, McConnell SK (1992) Diverse migratory pathways in the developing cerebral cortex. Science 258: 299-302.

Pawley JB, ed (1990) Ilandbook of biological confocal microscopy. New York: Plenum.

Sandell JH, Masland RH (1988) Photoconversion of some fluorescent markers to a diaminobenzidine product. J Histochem Cytochem 36: 555-559.

Schlessinger AR, Cowan WM, Gottlieb DI (1975) An autoradiographic study of the time of origin and the pattern of granule cell migration in the dentate gyrus of the rat. J Comp Neurol 159:149-176.

Smith SJ, Cooper M, Waxman A (1990) Laser microscopy of subcellular structure in living neocortex: can one see dendritic spines twitch? In: XXIII Symposia Medica Hoechst, Biology of memory (Squire L, Lindenlaub E, eds), pp 49-71. Stuttgart: Schattauer.
Stirling RV, Bliss TVP (1978) Hippocampal mossy fiber development at the ultrastructural level. Prog Brain Res 48:191-198.

Vaughn JE (1989) Fine structure of synaptogenesis in the vertebrate central nervous system. Synapse 3:255-285.

White WF, Nadler JV, Hamberger A, Cotman CW, Cummins JT (1977) Glutamate as transmitter of the hippocampal perforant path. Nature 270:356-357.

Yamamoto N, Kurotani T, Toyama K (1989) Neural connections between the lateral geniculate nucleus and visual cortex in vitro. Science 245:192-194.

Yamamoto N, Yamada K, Kurotani T, Toyama K (1992) Laminar specificity of extrinsic cortical connections studied in coculture preparations. Neuron 9:217-228.

Zimmer J (1978) Development of the hippocampus and fascia dentata: morphological and histochemical aspects. Prog Brain Res 48:171189.

Zimmer J, Gähwiler BH (1984) Cellular and connective organization of slice cultures of the rat hippocampus and fascia dentata. J Comp Neurol 228:432-446.

Zimmer J, Gähwiler BH (1987) Growth of hippocampal mossy fibers: a lesion and coculture study of organotypic slice cultures. J Comp Neurol 264:1-13.

Zimmer J, Haug F-MS (1978) Laminar differentiation of the hippocampus, fascia dentata and subiculum in developing rats, observed with the Timm sulphide silver method. J Comp Neurol 179:581618. 